Published in final edited form as:

Nature. 2017 March 16; 543(7645): 385-390. doi:10.1038/nature21697.

\title{
MC4R-dependent suppression of appetite by bone-derived lipocalin 2
}

\author{
Ioanna Mosialou ${ }^{1}$, Steven Shikhel ${ }^{1}$, Jian-Min Liu ${ }^{1, \dagger}$, Antonio Maurizi ${ }^{1, \dagger}, \mathrm{Na}^{\mathrm{L}} \mathrm{Lu}^{1}$, Zhenyan \\ $\mathrm{He}^{2,3}$, Yiru Huang ${ }^{2,3}$, Haihong Zong ${ }^{4}$, Richard A. Friedman ${ }^{5}$, Jonathan Barasch ${ }^{6}$, Patricia \\ Lanzano $^{7}$, Liyong Deng ${ }^{7}$, Rudolph L. Leibel ${ }^{7}$, Mishaela Rubin ${ }^{8}$, Thomas Nicholas ${ }^{9}$, Wendy \\ Chung $^{7}$, Lori M. Zeltser ${ }^{10}$, Kevin W. Williams ${ }^{3}$, Jeffrey E. Pessin ${ }^{4}$, and Stavroula Kousteni ${ }^{1}$ \\ ${ }^{1}$ Department of Physiology and Cellular Biophysics, College of Physicians and Surgeons, \\ Columbia University, New York, New York 10032, USA
}

${ }^{2}$ Department of Neurosurgery, Zhujiang Hospital, Southern Medical University, Guangzhou 510515, China

${ }^{3}$ Division of Hypothalamic Research, the University of Texas Southwestern Medical Center at Dallas, Dallas, Texas 75390-9077, USA

${ }^{4}$ Department of Medicine and Molecular Pharmacology, The Albert Einstein College of Medicine, Bronx, New York, New York 10461, USA

${ }^{5}$ Biomedical Informatics Shared Resource, Department of Biomedical Informatics, Herbert Irving Comprehensive Cancer Center, College of Physicians and Surgeons, Columbia University, New York, New York 10032, USA

${ }^{6}$ Department of Medicine, College of Physicians and Surgeons, Columbia University, New York, New York 10032, USA

${ }^{7}$ Naomi Berrie Diabetes Center and Division of Molecular Genetics, Department of Pediatrics, College of Physicians and Surgeons, Columbia University, New York, New York 10032, USA

${ }^{8}$ Metabolic Bone Disease Unit, Department of Medicine, College of Physicians and Surgeons, Columbia University, New York, New York 10032, USA

\footnotetext{
Reprints and permissions information is available at www.nature.com/reprints.

Correspondence and requests for materials should be addressed to S.K. (sk2836@cumc.columbia.edu).

†Present addresses: Department of Endocrine and Metabolic Diseases, Shanghai Rui-jin Hospital, Shanghai Jiao-tong University

School of Medicine, Shanghai 200025, China (J.-M.L.); Department of Biotechnological and Applied Clinical Sciences, University of L'Aquila, L'Aquila 67100, Italy (A.M.).

The authors declare no competing financial interests.

Readers are welcome to comment on the online version of the paper.

Publisher's note: Springer Nature remains neutral with regard to jurisdictional claims in published maps and institutional affiliations. Supplementary Information is available in the online version of the paper.

Author Contributions I.M. and S.K. initiated the study, designed experiments and analysed data. I.M. and S.S. performed experiments and analysed data. N.L., J.-M.L. and A.M. helped with ICV infusions and bone phenotyping. H.Z. performed hyperglycemic clamps. R.A.F. analysed microarray data. J.B. provided Len2-reporter mice. P.L., L.D., R.L.L. and W.C. provided plasma samples of patients with $M C 4 R$ mutations. M.R. and T.N. provided serum samples from men with type 2 diabetes. Z.H., Y.H. and K.W.W. performed the electrophysiology experiments. L.M.Z. and J.E.P. discussed data and manuscript. I.M. and S.K. wrote the manuscript. S.K. directed the research.
}

Reviewer Information Nature thanks M. Myers, R. Palmiter, M. Zaidi and the other anonymous reviewer(s) for their contribution to the peer review of this work. 
${ }^{9}$ Department of Medicine Nephrology, College of Physicians and Surgeons, Columbia University, New York, New York 10032, USA

${ }^{10}$ Naomi Berrie Diabetes Center and Department of Pathology and Cell Biology, Columbia University, New York, New York 10032, USA

\section{Abstract}

Bone has recently emerged as a pleiotropic endocrine organ that secretes at least two hormones, FGF23 and osteocalcin, which regulate kidney function and glucose homeostasis, respectively. These findings have raised the question of whether other bone-derived hormones exist and what their potential functions are. Here we identify, through molecular and genetic analyses in mice, lipocalin 2 (LCN2) as an osteoblast-enriched, secreted protein. Loss- and gain-of-function experiments in mice demonstrate that osteoblast-derived LCN2 maintains glucose homeostasis by inducing insulin secretion and improves glucose tolerance and insulin sensitivity. In addition, osteoblast-derived LCN2 inhibits food intake. LCN2 crosses the blood-brain barrier, binds to the melanocortin 4 receptor (MC4R) in the paraventricular and ventromedial neurons of the hypothalamus and activates an MC4R-dependent anorexigenic (appetite-suppressing) pathway. These results identify LCN2 as a bone-derived hormone with metabolic regulatory effects, which suppresses appetite in a MC4R-dependent manner, and show that the control of appetite is an endocrine function of bone.

Central signals as well as several hormones and circulating peptides influence food intake and/or energy expenditure in a coordinated manner to regulate body weight. Those include, but are not limited to leptin, insulin, glucagon-like peptide-1, cholecystokinin and peptide YY, which are produced in distinct peripheral organs and influence food intake by signalling in the hypothalamus, the brainstem or afferent autonomic nerves ${ }^{1-6}$. It is conceivable that, in addition to these known signals, other hormones exist, which control food intake.

Bone has emerged as an endocrine organ that can regulate energy metabolism. A hormone secreted by osteoblasts, osteocalcin (also known as Bglap), promotes energy expenditure, insulin secretion and glucose homeostasis in mice and humans ${ }^{7-10}$. Another hormone, FGF23, which is secreted by osteoblasts and osteocytes, acts on the kidney to regulate phosphate metabolism ${ }^{11}$. The identification of osteocalcin as a regulator of energy metabolism indicates that other hormones synthesized by bone cells may potentially affect additional aspects of energy metabolism. Studies have suggested that osteoblasts have an anorexigenic function in vivo ${ }^{12}$ and therefore we tried to identify anorexigenic signal(s) that originate from osteoblasts.

MC4R, which is expressed mainly in the paraventricular nucleus of the hypothalamus (PVH), regulates food intake, body weight and caloric efficiency in rodents and humans ${ }^{13-17}$. MC4R mutations in humans account for up to $5 \%$ of cases of childhood obesity and $0.5 \%$ to $2.5 \%$ of adult obesity, while deletion of $M c 4 r$ in mice results in hyperphagic obesity ${ }^{18-20}$. The anorexigenic signalling through MC4R is regulated by binding of MC4R to the anorexigenic a-melanocyte-stimulating hormone (a-MSH, the proteolytic cleavage product of pro-opiomelanocortin-a (Pomc)) and the orexigenic (appetite stimulating) Agouti-related protein (AGRP), which are released by different 
hypothalamic arcuate neurons. More recently, defensin $\beta 3$, which is produced mainly in skin, was shown to be a MC4R ligand. Defensin $\beta 3$ modulates MC4R signalling by inhibiting the action of a-MSH or AGRP ${ }^{21}$. These observations suggest that the list of MC4R-modulating proteins controlling food intake may not be complete.

We show that $\mathrm{LCN} 2$, a protein that was previously thought to be exclusively secreted by adipose tissue (an adipokine) and is associated with obesity, is expressed by osteoblasts, at levels that are at least tenfold higher in osteoblasts than in white adipose tissue or other organs. Osteoblast-derived LCN2 crosses the blood-brain barrier and suppresses appetite after binding to the MC4R in the hypothalamus. This result broadens our understanding of the control of appetite as well as the endocrine role of bone and identifies LCN2 as an osteoblast- derived hormone that activates the anorexigenic pathway in a MC4R-dependent manner.

\section{LCN2 is an osteoblast-enriched hormone}

Mice with osteoblast-specific knockdown of Foxol $\left(\mathrm{FoxOl}_{\mathrm{osb}^{-}}{ }^{--}\right.$) show improved energy metabolism, in part owing to osteocalcin activation ${ }^{10}$. Therefore, we searched for osteoblastsecreted molecules that regulate energy homeostasis downstream of FOXO1. Among them, the gene that encodes LCN2, a $25 \mathrm{kDa}$, secreted glycoprotein, was one of the most highly upregulated in osteoblasts (Supplementary Table 1), bone and serum of $\mathrm{FoxOl}_{\mathrm{osb}^{-1-}}$ mice (Fig. 1a, b). Because LCN2 has been considered an adipokine that is associated with obesity $^{22-24}$, we analysed LCN2 expression in all tissues and identified bone as the predominant organ where $L c n 2$ is expressed, with at least tenfold higher expression levels in bone than in white fat (Fig. 1c-e and Extended Data Fig. 1a, c). Lcn2 expression increased with osteoblast differentiation similar to osteocalcin and alkaline phosphatase (Extended Data Fig. 1b). Therefore, LCN2 is an osteoblast-enriched, secreted protein that is upregulated in $\mathrm{FoxO}_{\mathrm{osb}^{-1-}}$ mice, which have improved energy metabolism.

\section{Osteoblast-derived LCN2 decreases food intake}

To determine the cellular origin of LCN2, we generated mice that lacked LCN2 in osteoblasts $\left(L c n 2_{\mathrm{osb}^{-l-}}\right.$ ) or adipocytes $\left(L \mathrm{cn} 2_{\mathrm{osb}}{ }^{-/-}\right)^{25,26}$ (Extended Data Figs 1d-k, 2c). $\operatorname{Lcn} 2_{\mathrm{osb}^{-}}{ }^{--}$and $L c n 2_{\mathrm{fat}}{ }^{-/}$mice showed a $67 \%$ and $27 \%$ decrease in serum levels of LCN2, respectively. Osteoblast-derived and fat-derived LCN2 is the same protein (Extended Data Fig. 2a, b).

$\operatorname{Lcn} 2_{\mathrm{osb}^{-1-}}{ }^{-1}$ mice had compromised glucose metabolism, as was shown by decreased glucose tolerance, insulin sensitivity, a lack of insulin secretion after glucose or arginine challenge (Fig. 1f, h, j and Extended Data Fig. 3a, b), and 50\% reduction in insulin levels (Fig. 2a). Islet numbers and size, $\beta$-cell mass and $\beta$-cell proliferation were decreased in the pancreas of $L \mathrm{cn} 2_{\mathrm{osb}}{ }^{-1-}$ mice without changes in apoptosis, islet architecture or differentiation (Extended Data Fig. 3c-g). None of these parameters were affected in $L c n 2_{\mathrm{fat}}{ }^{-/-}$mice (Fig. 1g, i, k, 2b). In all experiments Col1a1-Cre mice were identical to wild-type litter-mates (Extended Data Fig. 3i-p). 
In spite of low circulating insulin levels and decreased insulin sensitivity, $L c n 2_{\mathrm{osb}}{ }^{-/-}$mice showed increased gonadal fat weight (16.5\%), total fat mass (19.6\%) and body weight (5\%), which was an expected magnitude of change since lean and bone mass were unaltered (Fig. $2 \mathrm{c}-\mathrm{e}) . L c n 2_{\mathrm{fat}^{-}}{ }^{-1-}$ mice did not show changes in fat or body weight (Fig. $2 \mathrm{f}-\mathrm{h}$ ). Expression of adipogenic factors increased, whereas expression of lipolytic factors decreased in $\mathrm{LCn}_{\mathrm{Osb}^{-1-}}$ mice (Extended Data Fig. 3q). Energy expenditure and sympathetic nervous system activity were similar in $\mathrm{Lcn}_{\mathrm{osb}^{-}}{ }^{--}$and control mice (Extended Data Fig. 3r-t). By contrast, 3month-old $L c n 2_{\mathrm{osb}^{-1-}}$ mice showed $16.4 \%$ increase in food intake, which persisted following normalization by body weight, whereas food intake was not affected in $L c n 2_{\mathrm{fat}}{ }^{-1-}$ mice (Fig. $2 \mathrm{i}$, j and Extended Data Fig. 3u). During growth, food intake was increased by $23.7 \%$ in 3week-old $L \mathrm{Cn} 2_{\mathrm{osb}}{ }^{-1-}$ mice and preceded the increase in body weight that manifested at 4 weeks of age (Fig. 2k, 1). These observations, and the lack of Adipoq-Cre expression in bone-marrow adipocytes ${ }^{27,28}$, indicate that neither bone marrow nor white fat contribute to an amount of LCN2 in circulation that can regulate appetite and glucose metabolism. These results also suggest that increased appetite accounts for the increase in body weight in $L c n 2_{\mathrm{osb}^{-}}{ }^{-/}$mice and may contribute to the development of glucose intolerance.

To examine this hypothesis, we pair-fed $L c n 2_{\mathrm{osb}^{-}}{ }^{--}$mice with their wild-type littermates. Body weight, fat mass and insulin sensitivity were normalized, whereas serum insulin levels and insulin secretion after glucose load remained compromised in $L c n 2_{\mathrm{osb}}{ }^{-1-}$ mice and as a result their glucose intolerance persisted (Extended Data Fig. 4a-f). Therefore, we examined whether LCN2 signals in $\beta$-cells directly to affect $\beta$-cell functions. LCN2 stimulated insulin secretion directly in primary pancreatic islets (Extended Data Fig. 3h). Therefore, the anorexigenic function of LCN2 influences fat mass, body weight and insulin sensitivity, whereas the ability of LCN2 to improve glucose tolerance probably reflects its direct action on pancreatic islets.

Inactivation of $L c n 2$ in osteoblasts using another osteoblast-specific line expressing Bglap-

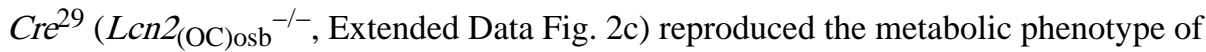
$L c n 2_{\mathrm{osb}^{-1-}}$ mice (Extended Data Fig. $4 \mathrm{~g}-\mathrm{q}$ ). Bone mass and osteocalcin expression and activity were not affected in $\mathrm{Lcn}_{\mathrm{osb}^{-/-}}$mice (Extended Data Fig. $4 \mathrm{r}-\mathrm{t}$ ), indicating that their metabolic phenotype is not secondary to a bone defect or changes in osteocalcin activity. Of note, osteocalcin does not regulate appetite ${ }^{7}$.

The biological significance of these observations was validated in humans. Serum levels of LCN2 inversely correlated with body weight and glycated haemoglobin $\left(\mathrm{HbA}_{1 \mathrm{c}}\right)$ in patients with type 2 diabetes mellitus (Fig. $2 \mathrm{~m}, \mathrm{n}$ ).

A physiological role for LCN2 in feeding regulation was found, as there was a threefold increase in serum levels of LCN2 1-3 h after refeeding wild-type mice after overnight fasting (Fig. 2o). The increase in LCN2 was owing to LCN production by osteoblasts, as it correlated with a 1.6-fold increase in $L c n 2$ expression in bone, but not in fat or other tissues (Extended Data Fig. 4u). Similarly, food intake was suppressed at 1-3 $\mathrm{h}$ after refeeding wild-type mice (Fig. 2p). 
$L c n 2_{\mathrm{osb}^{-}}{ }^{-/}$mice had higher cumulative food intake at all examined time points after refeeding and twofold higher rate of food intake at $2 \mathrm{~h}$ after refeeding (Fig. 2q). Intraperitoneal administration of $\mathrm{LCN} 2$ to fasted $L \mathrm{Ln} 2_{\mathrm{osb}}{ }^{-/-}$mice immediately after refeeding suppressed food intake within $1 \mathrm{~h}$ as efficiently as in wild-type mice. Thus, upregulation of $L c n 2$ expression by osteoblasts following feeding is an acute anorexi-genic signal to limit appetite after a meal in the mouse.

\section{LCN2 suppresses food intake in lean and obese mice}

We then investigated whether exogenous LCN2 could exert a sustained anorexigenic effect. Daily intraperitoneal administration of LCN2 (150 $\left.\mathrm{ng} \mathrm{g}^{-1}\right)$ to wild-type mice for 16 weeks increased serum LCN2 levels by twofold, an increase similar to that observed after postprandial upregulation of serum LCN2 levels (Extended Data Fig. 5a), and led to an 18\% decrease in food intake (Fig. 3a). Fat mass, body weight and body-weight gain decreased by 32\%, 9.4\% and 34\%, respectively (Fig. 3b, c and Extended Data Fig. 5b, c). Circulating insulin levels increased and glucose tolerance, insulin secretion and sensitivity and energy expenditure improved in LCN2-treated mice (Fig. 3d-f and Extended Data Fig. 5d-f). The identity and purity of the recombinant protein was verified by mass spectrophotometry (Extended Data Fig. 5g-h).

Treatment of mice with an inactive leptin receptor ( $L e p r^{d b / d b}$ mice $)^{30}$ with LCN2 for 16 weeks suppressed food intake, gonadal fat and body-weight gain by $16.5 \%, 22 \%$ and $26 \%$, respectively (Fig. 3g-i and Extended Data Fig. 5i). Glucose tolerance, insulin sensitivity and energy expenditure were improved in $L e p r^{d b / d b}$ mice treated with LCN2 (Fig. 3j and Extended Data Fig. 5j, k). These results indicate that LCN2 counteracts, at least in part, deleterious consequences of the lack of leptin signalling on appetite and energy expenditure. They also support observations that $L c n 2$ expression is upregulated in obesity to counteract adiposity, inflammation and insulin resistance ${ }^{22}$.

\section{LCN2 acts on the hypothalamus to suppress appetite}

Because $\mathrm{LCn} 2_{\mathrm{Osb}}{ }^{-1-}$ mice did not show changes in the expression of adipose- or gut-derived hormones that affect food intake (Extended Data Fig. 6a-g), we tested whether LCN2, which is not expressed in the hypothalamus (Fig. 1c, d and Extended Data Fig. 1a, c), can cross the blood-brain barrier and signal directly in the brain to regulate food intake.

LCN2 or vehicle was delivered intraperitoneally to $L \mathrm{cn} 2^{-/-}$mice. Notably, hyperphagia and the entire metabolic phenotype - and lack of changes in bone mass - of the global $\mathrm{Lcn} 2^{-1-}$ mice are identical, including in their magnitude, to those observed in $L \mathrm{Cn} 2_{\mathrm{osb}^{-l}}{ }^{-1}$ mice (Extended Data Fig. 6h-s). LCN2, at a dose restoring normal serum levels (107 $\mathrm{ng} \mathrm{ml}^{-1}$ ), accumulated in the brainstem, thalamus and mostly in the hypothalamus of $L \mathrm{cn} 2^{-/-}$mice within $2 \mathrm{~h}$ of treatment at levels similar to those of wild-type mice (Extended Data Fig. 6t). Fasting and subsequent refeeding of wild-type mice led to a twofold increase in LCN2 levels in the hypothalamus (Extended Data Fig. 6u). Intracerebroventricular (ICV) infusions in $\mathrm{LCn} 2^{-1-}$ mice, at a dose restoring normal LCN2 levels in the hypothalamus, normalized appetite in $\mathrm{Lcn} 2^{-/-}$mice and decreased body-weight gain by $5 \%$ (Fig. 4a, b). There was no 
leakage of centrally delivered LCN2 into the circulation (Extended Data Fig. 6v). ICV infusion of LCN2 decreased appetite and body-weight gain in wild-type mice with similar amplitude as ICV infusion of leptin or melanotan II (MT-II), a potent synthetic analogue of a-MSH (Fig. 4c-f). Therefore, LCN2 suppresses appetite in the mouse by signalling directly in the brain.

\section{LCN2 activates CAMP signalling in the hypothalamus}

We investigated how LCN2 suppresses food intake after signalling in the hypothalamus. LCN2 did not induce phosphorylation of AMPK, ERK1, ERK2 or tyrosine kinase but activated cAMP as efficiently as $0.5 \mathrm{nM}$ a-MSH, the equimolar amount of the most potent LCN2 dose (10 ng ml-1) in mouse GT1-7 hypothalamic cells (Fig. 4g, h). LCN2 dosedependently upregulated and subsequently downregulated cAMP activity. The same bellshaped response curve was observed in the regulation of appetite after ICV infusion of increasing concentrations of LCN2 in wild-type mice (Fig. 4i). These responses suggest receptor desensitization as seen in the case of signalling that is mediated by G-proteincoupled receptors ${ }^{31,32}$.

\section{LCN2 activates MC4R signalling in the hypothalamus}

Among all hypothalamic pathways that affect appetite, only the expression of downstream effectors of MC4R signalling was altered in $\mathrm{Lcn}_{\mathrm{osb}^{-}}{ }^{-/}$mice and in LCN2-treated wild-type mice (Extended Data Fig. 7a-d). Therefore, we analysed whether MC4R transduces LCN2 signals. Several lines of evidence supported this hypothesis. First, LCN2 dose-dependently induced cAMP activity in $M c 4 r$-expressing HEK293T cells with an $\mathrm{EC}_{50}$ (the half-maximal response) of $1.41 \pm 0.25 \mathrm{nM}$ (Fig. 5a and Extended Data Figs 7h, 8i). Although a-MSH stimulated cAMP with an $\mathrm{EC}_{50}$ of $0.09 \pm 0.01 \mathrm{nM}$, the potency of cAMP induction by LCN2 was higher compared to the effect of a-MSH in low, but physiologically relevant doses found in the brain $\left(10^{-12} \mathrm{M}\right.$ and $\left.10^{-11} \mathrm{M}\right)$. Second, silencing $M c 4 r$ or pharmacologically inhibiting its activity in GT1-7 cells abrogated LCN2-induced cAMP activity (Extended Data Fig. 7e-g). Third, LCN2 activated MC4R signalling in GT1-7 cells (Extended Data Fig. 7i-n). By contrast, among the two known LCN2 receptors, megalin (also known as Lrp2) is not expressed in GT1-7 cells, whereas silencing of Slc22a17 (known as 24p3R) did not affect LCN2 signalling (Extended Data Fig. 7o-t). Fourth, biotinylated LCN2, at a physiological dose in the hypothalamus $\left(25 \mathrm{pg} \mathrm{ml}^{-1}\right)$, bound to PVH neurons and neurons in the ventromedial nucleus of the hypothalamus (VMH) of $\mathrm{Lcn}^{-/-}$mice, where $M c 4 r$ is expressed ${ }^{33}$ (Fig. 5b and Extended Data Fig. 9a). Binding of LCN2-biotin was competitively displaced by an excess of unlabelled LCN2, and no signal was detected with GST-biotin. Binding of LCN2 was abolished in the hypothalamus of $M c 4 r$-deficient mice (Fig. 5b), or in GT1-7 cells where Mc4r was silenced by short-interfering RNA (siRNA) (Extended Data Fig. 7u). LCN2 binding was not detected in neurons of the arcuate nucleus of the hypothalamus.

LCN2 binds to MC4R in HEK293T cells with a dissociation constant $\left(K_{d}\right)$ of $51.39 \pm 4.78$ $\mathrm{nM}$ and competed for binding with a-MSH with an inhibitor constant $\left(K_{i}\right)$ of $46.34 \pm 1.11$ nM. By comparison, a-MSH bound to MC4R with a 4.5 -fold higher affinity $\left(K_{d}=11.93\right.$ 
$\pm 1.23 \mathrm{nM}$ ) than LCN2 and competed for binding with LCN2 with a $K_{i}$ of $12.63 \pm 1.10 \mathrm{nM}$

(Fig. 5c-e and Extended Data Fig. 8i). Leptin and AGRP were used as a negative and additional positive control, respectively. Similar to a-MSH, LCN2 bound to and activated cAMP signaling through the MC1 and MC3 receptors (Extended Data Fig. 8a-h). However, MC1R and MC3R do not regulate appetite ${ }^{34,35}$. Therefore, LCN2 binds to Mc4r-expressing hypothalamic neurons and activates MC4R signalling.

\section{LCN2 activates PVH neurons of the hypothalamus}

We investigated whether LCN2 signals directly in $M c 4 r$-expressing cells. ICV administration of LCN2 induced, with similar potency to MT-II, Fos expression in PVH neurons of wild-type (36\% of PVH neurons were activated by LCN2 and 35\% activated by MT-II), but not $\mathrm{Mc} \mathrm{r}^{-1-}$ mice (Fig. $5 \mathrm{f}$ and Extended Data Fig. 7v). To assess the effects on cellular activity of hypothalamic neurons, we targeted Sim1-expressing neurons in the PVH (PVH-Sim1) and Pomc- and Npy-expressing neurons in the arcuate nucleus for electrophysio-logical recordings (Extended Data Fig. 9b-d). A subpopulation of PVH-Sim1 neurons have been linked to $M c 4 r$ expression and activities related to energy balance and MC4R-mediated activation of PVH and anorexia ${ }^{15,36,37}$. Therefore, these functions of PVHSim1 neurons help to better define the effect of LCN2 on melanocortin signalling. PVHSim1 neurons were depolarized in the presence of LCN2 (1.25 pM; in control artificial cerebrospinal fluid (ACSF), resting membrane potential $(\mathrm{RMP})=-50.8 \pm 4.1 \mathrm{mV}$; in ACSF $+\mathrm{LCN} 2, \mathrm{RMP}=-43.2 \pm 3.3 \mathrm{mV} ; n=8$ in each group, $P<0.05)$. The remaining 12 neurons from the PVH remained unchanged in response to LCN2 (1.25 pM; in control ACSF, RMP = $-47.1 \pm 2.8 \mathrm{mV}$; in ACSF + LCN2, RMP $=-47.2 \pm 2.7 \mathrm{mV} ; n=12, P>0.05)($ Fig. $5 \mathrm{~g}, \mathrm{j})$. LCN2 $(1.25 \mathrm{pM})$ did not alter the resting membrane potential of any $N p y$ neurons (in control ACSF, RMP $=-43.5 \pm 1.4 \mathrm{mV}$; in ACSF $+\mathrm{LCN} 2, \mathrm{RMP}=-43.5 \pm 1.5 \mathrm{mV} ; n=26, P>$ 0.05 ) and Pomc neurons (in control ACSF, RMP $=-46.1 \pm 2.1 \mathrm{mV}$; in ACSF + LCN2, RMP $=-46.3 \pm 2.2 \mathrm{mV} ; n=13, P>0.05$ ) (Fig. 5h, i). These data support activation of PVH neurons by LCN2, which is independent of the activity within Pomc or NpylAgrp neurons of the arcuate nucleus.

\section{MC4R is necessary for regulation of appetite by LCN2}

To determine whether MC4R mediates the anorexigenic function of LCN2 in vivo we treated ${\mathrm{Mc} 4 \mathrm{r}^{-/}}^{-1}$ and wild-type mice with LCN2. LCN2 suppressed appetite and decreased body weight in wild-type but not in $M c 4 r^{-1-}$ mice (Fig. 6a-c). LCN2 treatment did not improve glucose metabolism in $\mathrm{Mc} \mathrm{r}^{-/-}$mice, although treatment improved energy expenditure, glucose tolerance and insulin sensitivity in wild-type mice (Extended Data Fig. 10a-d). Analysis of $L c n 2_{\mathrm{osb}}{ }^{+/-} /:: M c 4 r^{-/-}$mice showed a significant increase in appetite, body weight and fat mass, and decreased glucose tolerance and insulin sensitivity compared to $\mathrm{Lcn}_{\mathrm{osb}^{+/-}}$and $\mathrm{Mc}^{+} \mathrm{r}^{+/-}$mice (Fig. 6d-g and Extended Data Fig. 10e-k). Therefore, LCN2 suppresses appetite by signalling through MC4R.

To understand how LCN2 regulates MC4R signalling in humans, we measured LCN2 levels in the plasma of six patients with MC4R mutations and in six age-, gender- and body-massindex-matched control subjects who had normal MC4R sequences (Fig. 6h, i and Extended 
Data Fig. 101). LCN2 levels were two-fourfold increased in three out of the five young-adult patients and in the single paediatric patient with MC4R mutations, as expected for GPCR ligands when the GPCR carries inactivating mutations.

\section{Discussion}

We have identified a mode of endocrine regulation of energy metabolism by bone, which occurs through control of appetite. LCN2, which is secreted by osteoblasts, acts as a hormone that mediates an acute and chronic anorexigenic function of bone in lean and obese mice. Osteoblast-derived LCN2 crosses the blood-brain barrier, and binds to and activates MC4R in PVN neurons of the hypothalamus with potency similar to that of leptin and comparable to the potent a-MSH analogue, MT-II. In addition to appetite-suppressing activities, LCN2 regulates insulin secretion and increases insulin sensitivity and glucose tolerance.

At this time there is no experimental evidence to explain why bone would suppress food intake. It is possible that the food-suppressing function of the skeleton resembles the homeostatic role of leptin; a decrease in bone mass and Lcn2 expression could allow an increase in food intake to restore nutrient uptake and maintain body growth through skeletal growth and/or increase in bone mass. Independent of the reasons for this regulation of energy intake, the underlying mechanisms that regulate appetite, and the abnormal glucose metabolism and obesity that are associated with metabolic disease, have not yet been fully elucidated. In that respect, the role of the skeleton in the control of energy intake and homeostasis may provide new insights into the pathogenesis of these diseases.

Note added in proof: Two earlier studies reported that $L c n 2$ deficiency does not affect appetite $^{38,39}$. The reasons for the different results are not clear, but may be due to different methodology, including differences in generating the $L c n 2$-deficient mice. However, the effects of exogenous LCN2 support the conclusion drawn from our loss-of-function experiments.

Online Content Methods, along with any additional Extended Data display items and Source Data, are available in the online version of the paper; references unique to these sections appear only in the online paper.

\section{METHODS}

\section{Mice}

To generate tissue-specific $L c n 2$-deficient mice, a targeting vector containing LoxP sites within introns 2 and 6, and designed to delete a $1.9 \mathrm{~kb}$ genomic fragment comprising $L \mathrm{cn} 2$ exons 3-6, was electroporated into 129/B6 ES cells. The neomycin-resistance gene flanked by two FRT sites and driven by the human $\beta$-actin promoter was used for positive selection. The diphtheria toxin A gene (DTA) driven by the PGK promoter is incorporated into the $3^{\prime}$ end of the vector allowing for negative selection. After vector linearization with AsiSI and electroporation into 129/B6 ES cells, homologous recombinants were identified by Southern blot and PCR, and these were subsequently injected in C57BL/6 blastocysts to generate 
chimaeric mice that expressed the mutated allele. F1 heterozygotes originating from the intercross of chimaeric mice with wild-type C57BL/6 mice were screened for germline transmission of the mutant allele and bred with transgenic mice expressing the $F l p$ recombinase under the control of the $\beta$-actin promoter to generate mice carrying the $L \mathrm{cn} 2$ floxed, $\Delta$ neo/lacZ allele, $L c n 2^{f l l+}$ (C57BL/6J: 75\%; 129/B6: 25\%). $L c n 2^{f l l+}$ were crossed with Colla1-Cre ${ }^{25}$, Bglap-Cre ${ }^{29}$, Adipoq-Cre ${ }^{40}$ or EIIa-Cre transgenic mice to create mice with osteoblast-specific $\left(L c n 2_{\mathrm{Osb}^{+}}{ }^{+-}\right.$and $L c n 2_{(\mathrm{OC}) \mathrm{osb}^{+/-}}{ }^{+/}$, adipocyte-specific $\left(L c n 2_{\mathrm{fat}}{ }^{+/-}\right)$, or global deletion of $\operatorname{Lcn} 2\left(\mathrm{Lcn}^{-/-}\right.$mice) (C57BL/6J: 87.5\%; 129/B6: 12.5\%). Of note, the GTex database artificially shows that the Coll1al and Bglap genes are expressed in several tissues because bone as a positive control is not included in the expression panels of this database. Lcn2-heterozygous mice were intercrossed and animals homozygous for $L c n 2$ deletion in osteoblasts $\left(L c n 2_{\mathrm{osb}^{+-}}{ }^{+/}\right.$and $\left.L c n 2_{(\mathrm{OC}) \text { osb }}{ }^{+-}\right)$, adipocytes $\left(L c n 2_{\mathrm{fat}}{ }^{-/-}\right)$or global deletion of $\operatorname{Lcn} 2$ ( $\left(\mathrm{Cnn}^{-/-}\right.$mice) were obtained. C57BL/6J, ROSA ${ }^{\mathrm{mT} / \mathrm{mG}}$ (stock number 007676), homozygous and heterozygous leptin-receptor- deficient mice, B6.BKS(D)Leprdb/J (stock number 000697), and mice lacking $M c 4 r$, B6;129S4-Mc4t tm1Lowl/J (stock number 006414) were purchased from The Jackson Laboratory. Foxo1 ${ }_{\mathrm{osb}}{ }^{-1-} ;$ Lcn2-reporter mice that had a double-fusion reporter gene that encodes luciferase- 2 and mCherry (termed Lcn2-mCherry), Pomc-hrGFP, Npy-hrGFP and Sim1-cre mice have been described $^{10,15,41-43}$. All mice were housed under standard laboratory conditions $(12 \mathrm{~h}$ on/ off; lights on at 7:00) and temperature-controlled environment with food and water available ad libitum. In each experiment the mice used were of the same genetic background, as they were all littermates. 10-12-week-old male mice of all genotypes and female $\mathrm{Lcn}^{-{ }^{-l}}$ mice were used in all experiments unless otherwise stated. Investigators were blinded during experiments and outcome assessment. Mouse genotypes were determined by PCR; primer sequences are available upon request. All animal procedures were approved by the Columbia University Institutional Animal Care and Use Committee.

\section{Human samples}

Men age $\geq 18$ years old with type 2 diabetes were recruited through advertisement flyers. Type 2 diabetes was defined as HbA1c $¥ 6.5 \%$ (according to the IDF Diabetes Atlas 2015 (http://www.diabetesatlas.org)). Subjects were excluded if they had a history of disorders associated with altered skeletal structure or function such as chronic kidney disease, chronic liver disease, active malignancy, acromegaly, Cushing's syndrome, thyroid disease, hyper- or hypoparathyroidism or organ transplant. Additionally, subjects were excluded if they were currently using teriparatide, loop diuretics, anti-convulsive therapies, corticosteroids ( $>3$ weeks over the past 3 years), thiazolidinediones or SGLT2 inhibitors. Bisphosphonate and/or denosumab use within the past 12 months were also exclusion criteria. Fasting morning blood was drawn and serum was stored at $-80^{\circ} \mathrm{C}$. Patients with or without mutations in $M C 4 R$ were enrolled in a study on the genetic basis of obesity. Participants had blood drawn after an overnight fast, and plasma and the buffy coat were separated. Genomic DNA was purified and the coding sequence of $M C 4 R$ and at least 20 base pairs of flanking intronic sequence were Sanger sequenced and analysed for sequence variants using Sequencher. Primer sequences are available upon request. All studies were approved by the Columbia University Medical Center Institutional Review Board and informed written consent was obtained from all participants or their guardians. 


\section{Metabolic studies}

Glucose tolerance (GTT), insulin tolerance (ITT) and glucose- stimulated insulin secretion (GSIS) tests were performed as previously described ${ }^{10}$. For $L e p r^{d b / d b}$ mice, the dose of glucose during GTT was $1 \mathrm{~g}$ per $\mathrm{kg}$ body weight and the dose of insulin during ITT was 2.5 U per kg body weight. Hyperglycemic clamps were performed at Albert Einstein DRTC Animal Physiology Core, as previously described ${ }^{44}$. Insulin levels were measure by the insulin ELISA kit (Crystal Chem). Urine elimination of catecholamines (epinephrine and norepinephrine) was measured in acidified morning urine samples collected during three consecutive days by EIA (Bi-CAT, Alpco Diagnostics). Creatinine (Microvue creatinine assay kit, Quidel corp.) was used to normalize between urine samples. ELISAs were performed for measurement of LCN2 (R\&D Systems) and leptin (EMD Millipore) levels in the serum. TSE Labmaster (TSE systems) and Oxymax System (Columbus Instruments) were used for indirect calorimetry and food-intake measurements. After at least 48-h acclimation to the chambers, data collected for a 48-h period were analysed as per the manufacturer's recommendations. For fast-refeeding experiments, metabolic cages (Nalgene, Rochester, NY) were used and food intake calculated as the change of powdered food weight. Mice were individually housed, fed ad libitum and allowed to habituate to the cages for 3 days. Following the initial acclimation, mice were fasted for $16 \mathrm{~h}$ and refed $2 \mathrm{~h}$ after the start of the light phase for four consecutive days. Measurements of food intake after refeeding were collected from the last day. For pair-feeding experiments, mice were individually housed starting at 4 weeks of age. Pair feeding started at 5 weeks of age and continued for a period of 8 weeks. Food intake was measured daily, and $L c n 2_{\mathrm{osb}}{ }^{-1-}$ mice were provided every day with the average amount of food consumed by the $L c n 2^{f l / f l}$ littermates that were fed ad libitum on the previous day. Body composition was determined using Bruker Minispec nuclear magnetic resonance (Bruker Optics, Billerica, MA).

\section{LCN2 treatment}

Recombinant LCN2 was freshly diluted in phosphate-buffered saline at a concentration of $15 \mathrm{ng \mu l}^{-1}$ and administered to mice daily intraperitoneally (i.p.) at a dose of $10 \mu \mathrm{lg}^{-1}$. Control, vehicle-treated mice, were injected with phosphate-buffered saline. In the study with C57BL/6J wild-type mice, daily injections were initiated at 9 weeks for a period of 16 weeks. GTT, ITT and GSIS tests were performed at 8, 9 and 10 weeks after treatment initiation. Food intake and serum insulin were measured at the end of the treatment period (15 weeks). In the study with $L e p r^{d b / d b}$ mice injections were initiated at 12 weeks of age for a period of 16 weeks. $\mathrm{Mc}^{-1-}$ mice were injected daily with LCN2 for 8 weeks starting at 8 weeks of age. Mice were randomized so that body weight and body composition matched cohorts were used.

\section{Recombinant protein and LCN2 protein identification}

For the construction of the bacterial vector expressing LCN2 fused with GST, the cDNA encoding mature mouse LCN2 (residue 83-625) was subcloned into the BamHI/NotI sites of the pGEX-4T-3 vector (GE Healthcare). Purification of bacterially produced mouse recombinant $\mathrm{LCN} 2$ protein was performed as described ${ }^{7}$. In brief, the GST-LCN2 fusion protein was bacterially produced and purified on glutathione-sepharose $4 \mathrm{~B}$ beads according 
to standard procedures. After extensive washes, LCN2 was cleaved out from the GST moiety using thrombin. A HiTrap Benzamidine column was subsequently used to deplete the thrombin from the preparation. Purity and identity of the protein was assessed by SDSPAGE followed by Coomassie blue staining and microcapillary LC-MS/MS performed at Taplin Biological Mass Spectometry Facility (Harvard Medical School) as described below. Endotoxin concentration was determined as being below the detection limit.

For LCN2 protein identification by microcapillary LC-MS/MS, endogenous LCN2 protein was purified from flushed bone and adipocyte tissue extracts that were subjected to LCN2 antibody (AF1857, R\&D) immunoprecipitation. Eluates from LCN2 immunoprecipitation along with purified recombinant protein were analysed by SDS-PAGE followed by Coomassie blue staining. Bands corresponding to the LCN2 protein were excised and sent to the Taplin Biological Mass Spectometry Facility (Harvard Medical School). Following ingel trypsin digestion of the gel slice containing the LCN2 protein, the resulting peptides were extracted from the gel and separated on a nano-scale high-performance liquid chromatography (HPLC) capillary column. Eluted peptides were subjected to electrospray ionization and injection into an LTQ-Orbitrap mass spectrometer (Thermo Scientific). Peptides were detected, isolated and fragmented to produce a tandem mass spectrum of specific fragment ions for each peptide. Peptide sequences (and hence protein identity) were determined using the database search algorithm Sequest. Sequence coverage of the LCN2 recombinant protein was $71 \%$, whereas coverage of bone or fat-derived LCN2 was $44.5 \%$ and $43 \%$ respectively. Owing to the absence of tryptic sites in the first 47 amino acids of the protein, the $\mathrm{N}$ terminus was absent from all analyses. Of note, $\mathrm{LCN} 2$ has no sequence or structural similarity to any of the known MC4R ligands, $\alpha$-MSH, AGRP and defensin $\beta 3$. This is consistent with the lack of sequence or structural similarity between a-MSH, AGRP and defensin $\beta 3$. However, a search throughout the amino acid sequence of mouse LCN2 revealed the presence of an RGRW motif (amino acids 48-51) that biochemically resembles and may functionally mimic the binding motif of a-MSH to MC4R.

\section{Intracerebroventricular infusions}

Mice were anesthetized with avertin and placed on a stereotaxic instrument (Stoelting). The calvaria was exposed and a $0.7 \mathrm{~mm}$ hole was drilled upon bregma. A 28-gauge cannula (Brain infusion kit 2, Alzet) was implanted into the third ventricle. The cannula was secured to the skull with cyanoacrylate and attached with tubing to a primed osmotic pump (Alzet) placed in the dorsal subcutaneous space of the mouse. The rate of delivery was $0.25 \mu \mathrm{lh}^{-1}$ for 14 days.

For assessment of Fos induction by single-bolus injection, 12-week-old male mice were anesthetized by i.p. injection of ketamine/xylazine ( $100 \mathrm{mg}$ per $\mathrm{kg} / 10 \mathrm{mg}$ per $\mathrm{kg}$ ) and a chronic stainless steel guide cannula was implanted stereotaxically bilaterally into the PVH with the following coordinates: bregma $-0.7 \mathrm{~mm}$; midline $\pm 0.3 \mathrm{~mm}$; dorsal surface $4.3 \mathrm{~mm}$. Cannulas were secured to the skull with cyanocrylate adhesive gel. After a 12-day recovery and acclimation of mice to handling, mice were injected with saline $(4 \mu \mathrm{l}), \mathrm{LCN} 2(0.125 \mathrm{mg}$ $\left.\mathrm{ml}^{-1}\right)$ or MT-II $\left(0.125 \mathrm{mg} \mathrm{ml}^{-1}\right)$ through the internal/injector cannula using a $5-\mu 1$ Hamilton syringe. After $1 \mathrm{~h}$, mice were anesthetized with ketamine/xylazine and perfused 
transcardially with PBS and subsequently with $4 \%$ paraformaldehyde (PFA). Brains were post-fixed in $4 \%$ PFA/PBS for $16 \mathrm{~h}$ at $4{ }^{\circ} \mathrm{C}$, cryoprotected in $30 \%$ sucrose/PBS overnight, embedded in cryomatrix and sectioned at $10 \mu \mathrm{m}$. For Fos immunostaining, goat anti-Fos (sc-52-G, Santa Cruz Biotechnology) and Alexa Fluor 488 (A11055, Life Technologies) antibodies were used. To quantify Fos expression and calculate the average number of Fosresponsive neurons in each mouse three sequential matched brain sections containing the PVH from each mouse were selected and Fos-positive neurons in the PVH were counted.

\section{LCN2 brain measurements}

Following $2 \mathrm{~h}$ of i.p. injection of $L c n 2^{-/-}$mice with recombinant LCN2 or vehicle, blood vessels were extensively washed with PBS and the indicated brain regions were dissected out. Tissues were homogenized in ice-cold PBS supplemented with protease inhibitors and soluble fractions were used to measure LCN2 levels by ELISA (R\&D Systems) normalized to total protein concentration as determined by DC Protein Assay (Bio-Rad Laboratories). For the detection of lower LCN2 values in the serum of $\mathrm{LCn}^{-/-}$mice, a range of lower standards was used to generate the standard curve, ranging from $19.52 \mathrm{pg} \mathrm{ml}^{-1}$ to $2.5 \mathrm{ng} \mathrm{ml}$ -1 .

\section{Gene-expression analyses}

RNA isolation, cDNA preparation and real-time PCR analyses were carried out following standard protocols. For bone tissue analysis, bone-marrow cells were removed completely by extensively flushing the femurs with PBS. Trizol reagent was used for RNA extraction, random hexamers cDNA synthesis kit (Clontech Laboratories) for reverse transcription PCR and SYBR Green Master Mix (Bio-Rad Laboratories) for quantitative PCR. Actb was used as an internal control. Data are presented as fold change over control, unless otherwise indicated. Primer sequences are available upon request.

\section{Histological analysis}

Bone histomorphometry analyses were performed as previously described ${ }^{45}$. In brief, lumbar vertebrae were dissected, fixed, dehydrated and embedded in methyl metacrylate (MMA). Von Kossa, toluidine blue and tartrate-resistant acid phosphatase (TRAP) staining were used to measure bone volume over tissue volume (BV/TV), osteoblasts and osteoclasts number, respectively. For pancreas histological analysis, the procedure described previously ${ }^{10}$ was followed. In brief, samples were fixed in $10 \%$ neutral formalin, embedded in paraffin and sectioned at $5 \mu \mathrm{m}$. Immunohistochemistry was performed using guinea- pig anti-insulin (A0564, Dako), rabbit anti-glucagon (A0565, Dako) and rabbit anti-Ki67 (ab16667, Abcam) antibodies. DeadEnd Colorimetric TUNEL assay (Promega) was performed to assess apoptosis. Osteomeasure software and a Leica DM 5000B microscope outfitted with CCD camera (Sony) was used for pancreas and bone histomorphometric analysis. For cryosection preparation from tissues of reporter mice, tissues were isolated from mice perfused with $4 \%$ PFA/PBS, fixed in $4 \%$ PFA/PBS for $4-24 \mathrm{~h}$ at $4{ }^{\circ} \mathrm{C}$, cryoprotected in $30 \%$ sucrose/PBS overnight, embedded in cryomatrix (Tissue-Tek) and sectioned at $10 \mu \mathrm{m}$. Bone samples were decalcified for $48 \mathrm{~h}$ before cryoprotection and embedding. Immunohistochemical analysis of samples from Lcn2-Luc2-mCherry and Crereporter mice was performed using anti-mCherry (ab167453, Abcam), anti-GFP (632375, 
Clontech Laboratories) and anti-RFP (600-401-379, Rockland Immunochemicals) antibodies, respectively. Alexa Fluor 488 and 594 (A11029 and A21207, Life Technologies) were used for signal detection. Experiments were repeated at least three times and representative images are presented.

\section{Brain-binding assay}

$\mathrm{Lcn} 2^{-/-}$or $\mathrm{Mc}_{4} \mathrm{r}^{-/-}$brains were snap-frozen in liquid nitrogen, and $10-\mu \mathrm{m}$ sections were prepared and desiccated overnight at $4{ }^{\circ} \mathrm{C}$ under vacuum. The following day brain sections were rehydrated in ice-cold binding buffer ( $50 \mathrm{nM}$ Tris- $\mathrm{HCl}(\mathrm{pH} 7.4), 10 \mathrm{nM} \mathrm{MgCl}_{2}, 0.1$ $\mathrm{mM}$ EDTA and $0.1 \% \mathrm{BSA}$ ) for $15 \mathrm{~min}$ and incubated $1 \mathrm{~h}$ at room temperature in the presence of biotinylated LCN2 $\left(25 \mathrm{pg} \mathrm{ml}^{-1}\right)$ or biotinylated GST as a control. After washing in harvesting buffer (50 mM Tris-HCl (pH 7.4)), samples were fixed in 4\% PFA for 15 min, washed in PBS, and incubated with goat anti-biotin antibody (SP-3000, Vector Laboratories) overnight at $4{ }^{\circ} \mathrm{C}$. The signal was visualized, after incubation with anti-goat Alexa Fluor 488 (A11055, Life technologies) followed by DAPI counterstaining, using an Olympus Bx53F microscope. To test for assay specificity, the procedure described above was performed in the presence of 100-fold excess of non-biotinylated LCN2 or GST $\left(2.5 \mathrm{ng} \mathrm{ml}^{-1}\right)$. Experiments were repeated three times and representative images are presented.

\section{Electrophysiology studies}

Brain slices were prepared from young adult male mice (5-8 weeks old) as previously described ${ }^{46,47}$. In brief, male mice were deeply anaesthetized with an i.p. injection of $7 \%$ chloral hydrate and transcardially perfused with a modified ice-cold artificial CSF (ACSF) (described below). The mice were then decapitated, and the entire brain was removed, and immediately submerged in ice-cold, carbogen-saturated $\left(95 \% \mathrm{O}_{2}\right.$ and $\left.5 \% \mathrm{CO}_{2}\right)$ ACSF (126 $\mathrm{mM} \mathrm{NaCl}, 2.8 \mathrm{mM} \mathrm{KCl}, 1.2 \mathrm{mM} \mathrm{MgCl} 2,2.5 \mathrm{mM} \mathrm{CaCl}_{2}, 1.25 \mathrm{mM} \mathrm{NaH}_{2} \mathrm{PO}_{4}, 26 \mathrm{mM}$ $\mathrm{NaHCO}_{3}$ and $5 \mathrm{mM}$ glucose). Coronal sections $(250 \mu \mathrm{m})$ were cut with a Leica VT1000S vibratome and then incubated in oxygenated ACSF at room temperature for at least $1 \mathrm{~h}$ before recording. The slices were bathed in oxygenated ACSF $\left(32{ }^{\circ} \mathrm{C}-34{ }^{\circ} \mathrm{C}\right)$ at a flow rate of $\sim 2 \mathrm{ml} \mathrm{min}^{-1}$. All electrophysiology recordings were performed at room temperature.

The pipette solution for whole-cell recording was modified to include an intracellular dye (Alexa Fluor 350 hydrazide dye) for whole-cell recording: $120 \mathrm{mM} \mathrm{K}$-gluconate, $10 \mathrm{mM}$ $\mathrm{KCl}, 10 \mathrm{mM}$ HEPES, $5 \mathrm{mM}$ EGTA, $1 \mathrm{mM} \mathrm{CaCl}_{2}, 1 \mathrm{mM} \mathrm{MgCl}_{2}$ and $2 \mathrm{mM} \mathrm{MgATP}, 0.03$ $\mathrm{mM}$ Alexa Fluor 350 hydrazide dye (pH 7.3). Epifluorescence was briefly used to target fluorescent cells, at which time the light source was switched to infrared differential interference contrast imaging to obtain the whole-cell recording (Zeiss Axioskop FS2 Plus equipped with a fixed stage and a QuantEM:512SC electron-multiplying charge-coupled device camera). Electrophysiological signals were recorded using an Axopatch 700B amplifier (Molecular Devices), low-pass filtered at 2-5 kHz, and analysed offline on a PC with pCLAMP programs (Molecular Devices). Membrane potential and firing rate were measured by whole-cell current-clamp recordings from neurons in brain slices. Targeting of Pomc and Npy neurons was anatomically restricted to the arcuate nucleus of the hypothalamus, whereas $\operatorname{Sim} 1$ neurons were targeted within the paraventricular nucleus of 
the hypothalamus. Recording electrodes had resistances of 2.5-5 $\mathrm{M} \Omega$ when filled with the K-gluconate internal solution.

LCN2 (1.25 pM) was added to the ACSF for specific experiments. Solutions containing drug were typically perfused for $5 \mathrm{~min}$. A drug effect was required to be associated temporally with peptide application, and the response had to be stable within a few minutes. A neuron was considered depolarized or hyperpolarized if a change in membrane potential was at least $2 \mathrm{mV}$ in amplitude.

\section{Cell culture and treatment}

HEK293T (obtained from ATCC) and hypothalamic GT1-7 cells (obtained from The Salk Institute $)^{48}$ were maintained in DMEM (25 mM glucose) supplemented with $10 \% \mathrm{FBS}$ and $100 \mathrm{U} \mathrm{ml}^{-1}$ penicillin and $100 \mu \mathrm{g} \mathrm{ml}^{-1}$ streptomycin and cultured at $37{ }^{\circ} \mathrm{C}$ in a $5 \% \mathrm{CO}_{2}$ atmosphere. INS1 cells (obtained from ThermoFisher Scientific) were maintained in RPMI supplemented with $10 \% \mathrm{FBS}, 10 \mathrm{mM}$ HEPES, $1 \mathrm{mM}$ sodium pyruvate, $50 \mu \mathrm{M} \beta$ merchaptoethanol and $100 \mathrm{U} \mathrm{ml}^{-1}$ penicillin and $100 \mu \mathrm{g} \mathrm{ml} \mathrm{g}^{-1}$ streptomycin and cultured at $37{ }^{\circ} \mathrm{C}$ in a $5 \% \mathrm{CO}_{2}$ atmosphere. Cell lines were tested and found to be free of mycoplasma. GT1-7 cells were authenticated by examining the expression of their specific panel of genes as described in ref. 48. For LCN2/a-MSH treatment and gene expression analysis in GT1-7, cells were serum starved overnight in DMEM supplemented with 0.5\% FBS before being treated with various concentrations of LCN2, a-MSH or vehicle for $4 \mathrm{~h}$. Primary islets were isolated as described previously ${ }^{8}$. For isolation of primary osteoblasts, calvaria from 3-dayold mice were digested in $1 \mathrm{mg} \mathrm{ml}^{-1}$ collagenase (Worthington Biochemical) for $1 \mathrm{~h}$ at $37^{\circ} \mathrm{C}$ with shaking, filtered, washed in aMEM and cultured in aMEM supplemented with $10 \% \mathrm{FBS}$ and $100 \mathrm{U} \mathrm{ml}^{-1}$ penicillin and $100 \mu \mathrm{g} \mathrm{ml}^{-1}$ streptomycin. When cells reached confluence, medium was supplemented with $5 \mathrm{mM} \beta$-glycerolphosphate and $100 \mu \mathrm{g} \mathrm{ml}^{-1}$ ascorbic acid (mineralization medium) which was replaced every 2 days thereafter. All experiments were repeated at least three times in triplicate.

\section{Binding assays}

For binding assays, a 100-mm dish of HEK293T cells was transfected with $10 \mu \mathrm{g}$ of the expression construct containing $M C 4 R, M C 3 R$ or $M C 1 R$ (purchased from Origene Technologies) using Lipofectamine 2000 (Invitrogen, Chicago, IL) according to the manufacturer's instructions. Transfection efficiency was tested by real-time PCR. Subsequently, $36 \mathrm{~h}$ after transfection, cells were dissociated with an enzyme-free celldissociation buffer (Life Technologies), washed with PBS and plated on white CoStar 96well plates pretreated with gelatin. For saturation binding assays and calculation of the dissociation constant, $K_{d}, 24 \mathrm{~h}$ later cells were washed with binding medium (0.5\% BSA in $\mathrm{Ca}^{2+} / \mathrm{Mg}^{2+} \mathrm{PBS}$ ) and incubated with serial dilutions of biotinylated protein in binding medium for $2 \mathrm{~h}$ at $37^{\circ} \mathrm{C}$. Protein biotinylation was performed using the EZ-Link NHS$\mathrm{PEG}_{4}$-biotinylation kit from Fisher Scientific. Following washes with binding medium, cells were fixed with $4 \%$ PFA for 10 min, washed with binding medium supplemented with $0.3 \%$ Triton X-100 and further incubated for 30 min with extra-avidin peroxidase (Sigma-Aldrich) in binding buffer. Cells were extensively washed and bound peroxidase was quantified using TMB substrate (Thermo Fisher Scientific). The reaction was terminated by addition of TMB 
stop solution (Immunochemistry Technologies) and absorbance was read at $450 \mathrm{~nm}$ in a Fluostar Omega (BMG Labtech) microplate reader. Non-specific binding was determined in the presence of $100 \mu \mathrm{m}$ non-biotinylated protein and specific binding was calculated by subtracting absorbance values for nonspecific binding from total binding values. Control experiments were performed using the maximum amount of biotinylated protein and HEK293T cells transiently transfected with the pcDNA3.1 vector alone, but no signal was detected. For competition binding assays, $50 \mathrm{nM}$ and $10 \mathrm{nM}$ of biotinylated LCN2 and aMSH (Sigma-Aldrich), respectively, (corresponding to their $K_{d}$ values) were added together with serial dilutions of non-biotinylated protein ranging from $10^{-11}$ to $10^{-5} \mathrm{M}$ and the procedure described above for determination of binding affinities was followed.

Recombinant human AGRP (aa 83-132) and mouse leptin proteins were purchased from $R \& D$. The incubation time that is sufficient to ensure that equilibrium has been reached was determined by kinetic experiments. Biotinylated a-MSH $(10 \mathrm{nM})$ was incubated in the presence of $10 \mathrm{nM} \mathrm{LCN2}$ and specific binding was determined at various time points thereafter, For binding assays in GT1-7, cells were transiently transfected with $100 \mathrm{nM}$ control siRNA (si-scramble) or siRNAs against $M c 4 r$ (Dharmacon) using Lipofectamine 2000. Silencing efficiency was tested by real-time PCR. Subsequently, $36 \mathrm{~h}$ after transfection, cells were dissociated, washed with PBS and plated on white CoStar 96-well plates. The cells were treated $24 \mathrm{~h}$ later with $60 \mathrm{ng} \mathrm{ml}^{-1}$ biotinylated LCN2 or equimolar amounts of a-MSH and binding assays were performed as described above. Binding data were analysed using Graphpad Prism Software. All experiments were repeated four times in triplicate.

\section{cAMP assays}

For cAMP quantification in GT1-7, cells were serum starved overnight (0.5\% FBS), preincubated in the presence of $0.5 \mathrm{mM}$ IBMX for $30 \mathrm{~min}$ at $37{ }^{\circ} \mathrm{C}$ and then stimulated with various amounts of LCN2 in the presence of $0.5 \mathrm{mM}$ IBMX for $15 \mathrm{~min}$. cAMP concentration was measured by ELISA (Enzo Life Sciences) and data were normalized to total protein content measured by DC Protein Assay. a-MSH was used as a positive control. For determination of cAMP production in the presence of SHU9119 (Tocris, Bioscience), cells were pretreated with $10 \mu \mathrm{M}$ of the antagonist for $1 \mathrm{~h}$ before LCN2 treatment. For determination of cAMP production in the absence of receptors, $48 \mathrm{~h}$ before LCN2 treatment (60 $\mathrm{ng} \mathrm{ml}^{-1}$ ), cells were transiently transfected with $100 \mathrm{nM}$ ON-TARGETplus SMARTpool siRNA targeting $M c 4 r$ or Slc22a17 or control (Dharmacon) using Lipofectamine 2000. For dose-response assays and calculation of $\mathrm{EC}_{50}$, HEK293T cells were transiently transfected with $10 \mu \mathrm{g}$ of pCRE/luciferase (pCRE-luc), a cAMP-inducible luciferase-expressing plasmid along with $10 \mu \mathrm{g}$ of the expression construct containing $M C 4 R, M C 3 R$ or $M C 1 R$. pRL-CMV Renilla (Promega) was used as an internal control. $24 \mathrm{~h}$ later, cells were dissociated, washed with PBS and plated on white CoStar 96-well plates. $48 \mathrm{~h}$ after transfection, cells were serum starved $(0.5 \%$ FBS $)$ overnight, pre-incubated in the presence of $0.5 \mathrm{mM}$ IBMX for $30 \mathrm{~min}$ at $37^{\circ} \mathrm{C}$ and then stimulated with increasing amounts of LCN2, a-MSH or leptin in the presence of $0.5 \mathrm{mM}$ IBMX for $15 \mathrm{~min}$ at $37^{\circ} \mathrm{C}$. Luciferase activity was determined using the Dual-Glo Luciferase Assay System (Promega) and quantified using Fluostar Omega. Luciferase activity was normalized to renilla activity and is presented as relative luciferase activity over vehicle-treated cells. Control experiments 
were performed using HEK293T cells transiently transfected with pCRE-luc or the $M C 4 R$ expression construct alone but no signal was detected. Data were analysed using Graphpad Prism Software. Experiments were repeated at least four times in triplicate.

\section{Western blotting}

For bone tissue analysis, bone-marrow cells were removed completely by flushing the femurs extensively with PBS. Tissue extracts from wild-type mice were analysed on SDSpolyacrylamide gel, transferred to a nitrocellulose membrane and probed with LCN2 (AF1857, R\&D) and GAPDH (14C10, Cell Signaling Technology) antibodies following standard procedures. For signal-transduction pathways in GT1-7 cells, cells were serum starved overnight in DMEM supplemented with $0.5 \%$ FBS and then stimulated with various amounts of LCN2 for 5 or 15 min as indicated. Cells were lysed and analysed by western blotting using the following antibodies: anti-cFos (7963, Abcam) anti-pERK1/ERK2 (4370), anti-pAMPK (2531), anti-p-tyrosine (9416), anti-pCREB (9198), anti-ERK1/ERK2 (total ERK1/ERK2, 9102), anti-AMPK (total AMPK, 2532) and anti-CREB (4820) from Cell Signaling Technology. Anti- $\beta$-actin (sc-47778, Santa Cruz Biotechnology) was used as an internal loading control. Experiments were repeated at least three times and representative images are presented. Gel source data are provided in Supplementary Fig. 1.

\section{Northern blotting}

Trizol reagent was used for RNA extraction from tissues of C57BL/6J mice according to the manufacturer's instructions. For bone tissue analysis, bone-marrow cells were removed completely by flushing the femurs extensively with PBS. $10 \mu \mathrm{g}$ total RNA was resolved on formaldehyde-agarose gels followed by transfer onto an Ambion BrightSTar-Plus membrane and hybridization with a ${ }^{32} \mathrm{P}$-labelled probe in Ultrahyb (Ambion, Thermo Fisher Scientific). A $\beta$-actin-specific probe was used as an internal control. Uncropped images are provided in Supplementary Fig. 1.

\section{Microarray analysis}

Total RNA was extracted from primary osteoblasts isolated from mouse calvaria using Trizol reagent (Invitrogen). Microarray analysis was performed using the GeneChip 3' IVT express kit and mouse genome 4302.0 array gene chips (Affymetrix) according to the manufacturer's instructions. In brief, anti-sense RNA was synthesized from $500 \mathrm{ng}$ of RNA and was biotinylated followed by purification and fragmentation using the GeneChip 3' IVT express kit. Fragmented aRNA was hybridized to Affymetrix mouse genome 4302.0 array gene chips. Following hybridization, chips were scanned with a GeneChip Scanner 3000 7G (Affymetrix). Data were normalized using the Mas5 method, and then $\log _{2}$ transformed. Data were deposited in Gene Expression Omnibus previously (accession number GSE43242). Differential expression was analysed using LIMMA. We focused on genes which code for secreted molecules (Gene Ontology ${ }^{49}$ Accession number GO:0005615 extracellular space) with Benjamini-Hochberg ${ }^{50}$ raw $P<0.1$ FDR $₫ 0.33$ and $\mid \log _{2}$ FC $\geq 2 \mid$. For a given gene, only the transcript with the lowest $P$ value is given in Extended Table 1. 


\section{Statistical analysis}

Results are presented as mean \pm s.e.m. Unpaired, two-tailed Student's $t$-test was performed for comparisons between two groups and one-way ANOVA for comparisons of more than two groups. For all experiments $* P \leq 0.05$ or ${ }^{\#} P \leq 0.05$. Effect size between wild-type and $L \mathrm{Cn} 2_{\mathrm{osb}}{ }^{-/}$mice was calculated according to the formulae from ref. 51. Sample-size determinations were based on the means and variances of preliminary data to achieve $80 \%$ power and a 5\% experiment-wise error rate assuming either an analysis of covariance (ANCOVA) parametric design for cross-sectional comparisons or a repeated measures analysis of variance (rmANOVA) for metabolic studies in mice.

\section{Data availability}

All data supporting the findings of this study are available within the paper and Supplementary Information. Source Data for all figures are provided with the paper. Uncropped versions of the gel images are provided in Supplementary Fig. 1. 


\section{Extended Data}
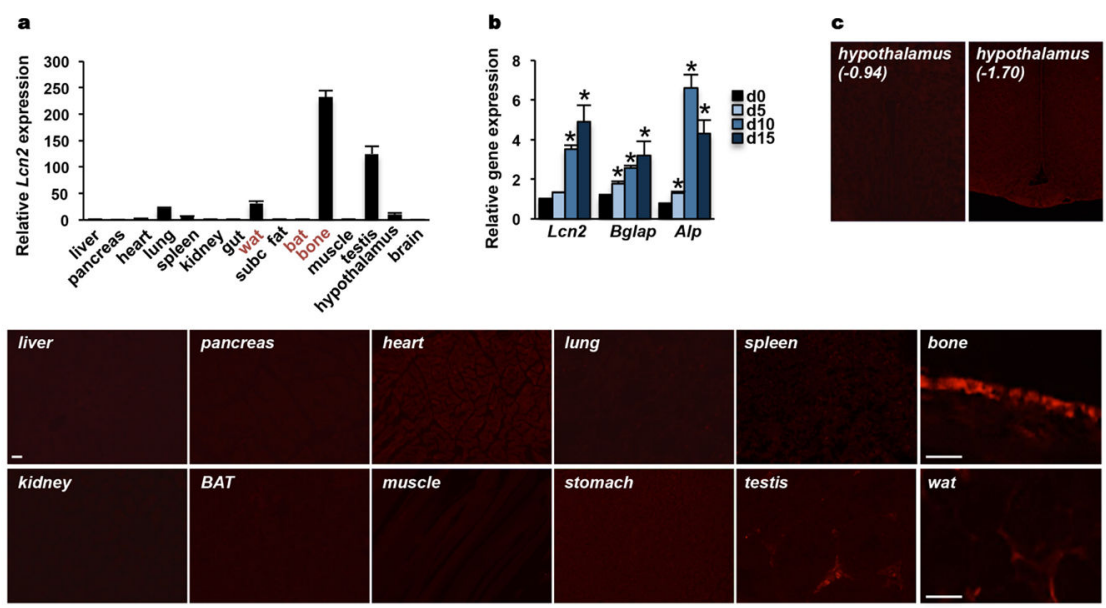

d
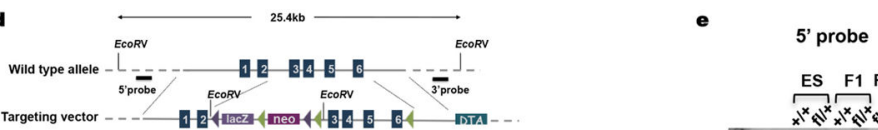

ES F1 F2
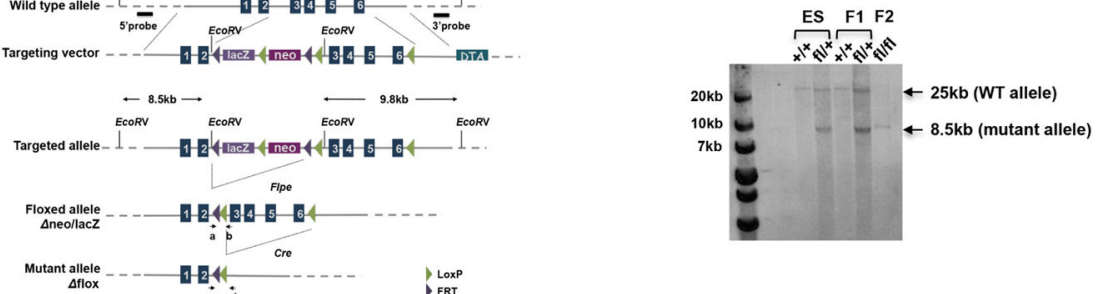

$\mathbf{f}$
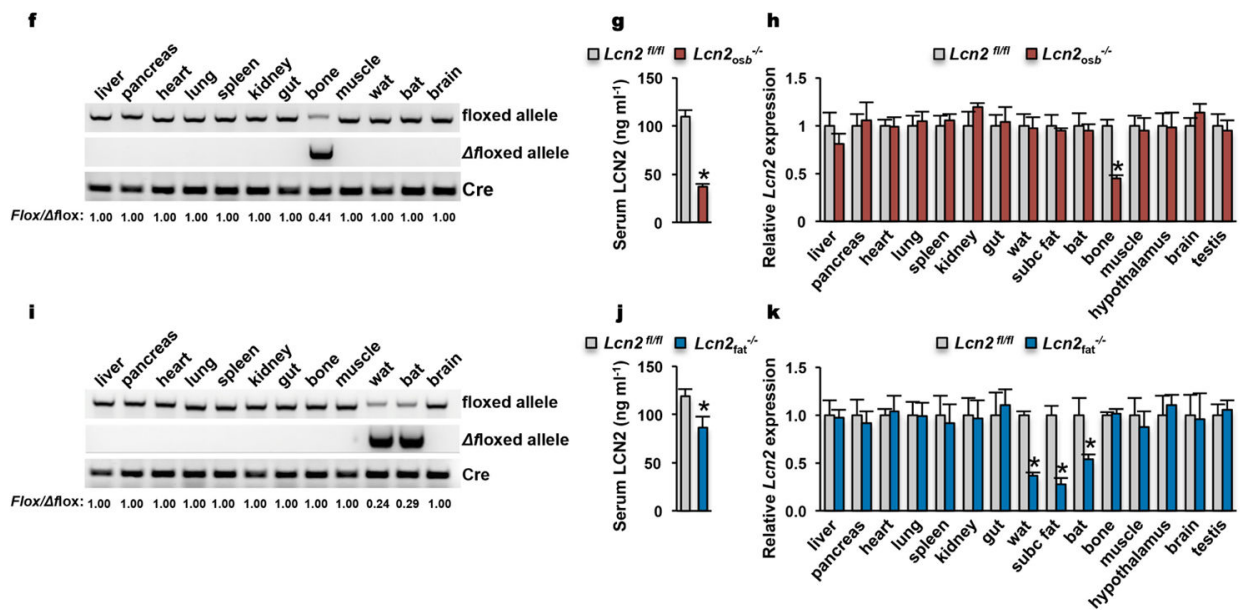

Extended Data Figure 1. Identification of $L c n 2$ as an osteoblast-enriched gene and generation of mice lacking $L c n 2$ in osteoblasts $\left(L c n 2_{0 s b}{ }^{-1-}\right)$ and adipocytes $\left(\operatorname{Lcn}_{\mathrm{fat}^{-1-}}\right)$

a, Real-time PCR analysis of Lcn2 expression levels in the indicated tissues from wild-type mice. b, Lcn2, Bglap and Alp expression levels in differentiating osteoblasts (day 0-day 15). c, Lack of Lcn2 expression in indicated tissues of the Lcn2-mCherry-reporter mouse. Scale bars, $40 \mu \mathrm{m}$. d, Targeting strategy used to generate a floxed allele of $L c n 2$. The targeting vector, which contains loxP sites within introns 2 and 6 , is designed to delete a $1.9 \mathrm{~kb}$ genomic fragment containing Lcn2 exons 3-6. Location of probes used for Southern blotting $\left(5^{\prime}\right.$ and $\left.3^{\prime}\right)$ and primers used for PCR to detect the floxed (a and b) and mutant allele (c and 
d) are indicated. e, Southern-blot analysis on DNA from targeted embryonic stem (ES) cells and mice from F1 and F2 generation showing germline transmission of the mutated allele. $\mathbf{f}$, i, Detection of $L c n 2$ floxed (primers a-b) and mutant allele, $\Delta$ flox, (primers $\mathrm{c}-\mathrm{d}$ ) in genomic DNA isolated from tissues of $L c n 2_{\mathrm{Osb}}{ }^{-/-}$(f) and $L c n 2_{\mathrm{fat}^{-1-}}$ (i) mice. $L c n 2_{\mathrm{osb}}{ }^{-1-}$ mice showed $60 \%$ recombination efficiency and 55\% decrease in Lcn2 expression specifically in bone, but not in other tissues. $L c n 2_{\mathrm{fat}^{-}}{ }^{-1-}$ mice showed $76 \%$ recombination efficiency in fat, which led to $65 \%$ and $50 \%$ decrease in Lcn2 expression in white and brown fat, respectively. $\mathbf{g}, \mathbf{j}$, Serum levels of LCN2 are decreased by $67 \%$ in $L c n 2_{\mathrm{osb}}{ }^{-1-}$ mice compared to their Lcn $2^{f l / f 1}$ littermates (g), whereas levels are decreased by $27 \%$ in $L c n 2_{\mathrm{fat}^{-1-}}$ mice compared to their $L c n 2^{f l / f l}$ littermates (j). h, k, Tissue expression of $L c n 2$ in $L c n 2_{\mathrm{osb}}{ }^{-/-}$and their $L c n 2^{f l / f l}$ littermates (h) and $L c n 2_{\mathrm{fat}}{ }^{-/-}$and their $L c n 2^{f l / f 1}$ littermates (k). Data are mean \pm s.e.m.; $n=$ 12 (a) and $n=9(\mathbf{g}, \mathbf{h}, \mathbf{j}, \mathbf{k})$ mice per group. Results are representative of three independent experiments. $* P<0.05$ (Student's $t$-test). 

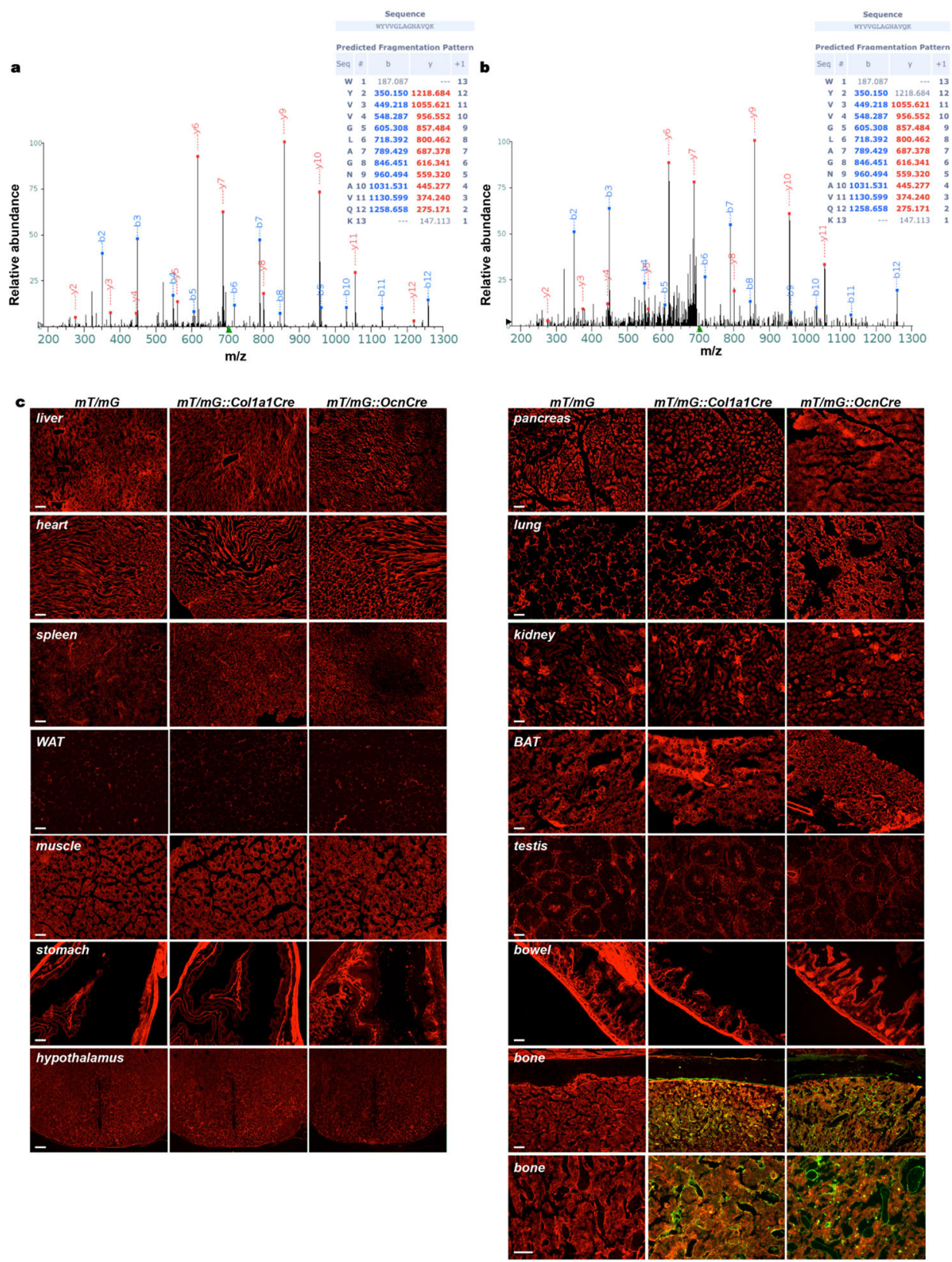

Extended Data Figure 2. Osteoblast-specific activation of Cre in Colla1-Cre and Bglap-Cre mice $\mathbf{a}, \mathbf{b}$, Tandem mass spectrum of an eluted peptide fragment of bone-derived (a) and fatderived (b) LCN2. c, Specific expression of Cre in osteoblasts, but not any other tissues in $\mathrm{mT} / \mathrm{mG}::$ Col1a1-Cre mice and in mT/mG::Bglap-Cre mice. Scale bars, $100 \mu \mathrm{m}$. Results are representative of three independent experiments. 

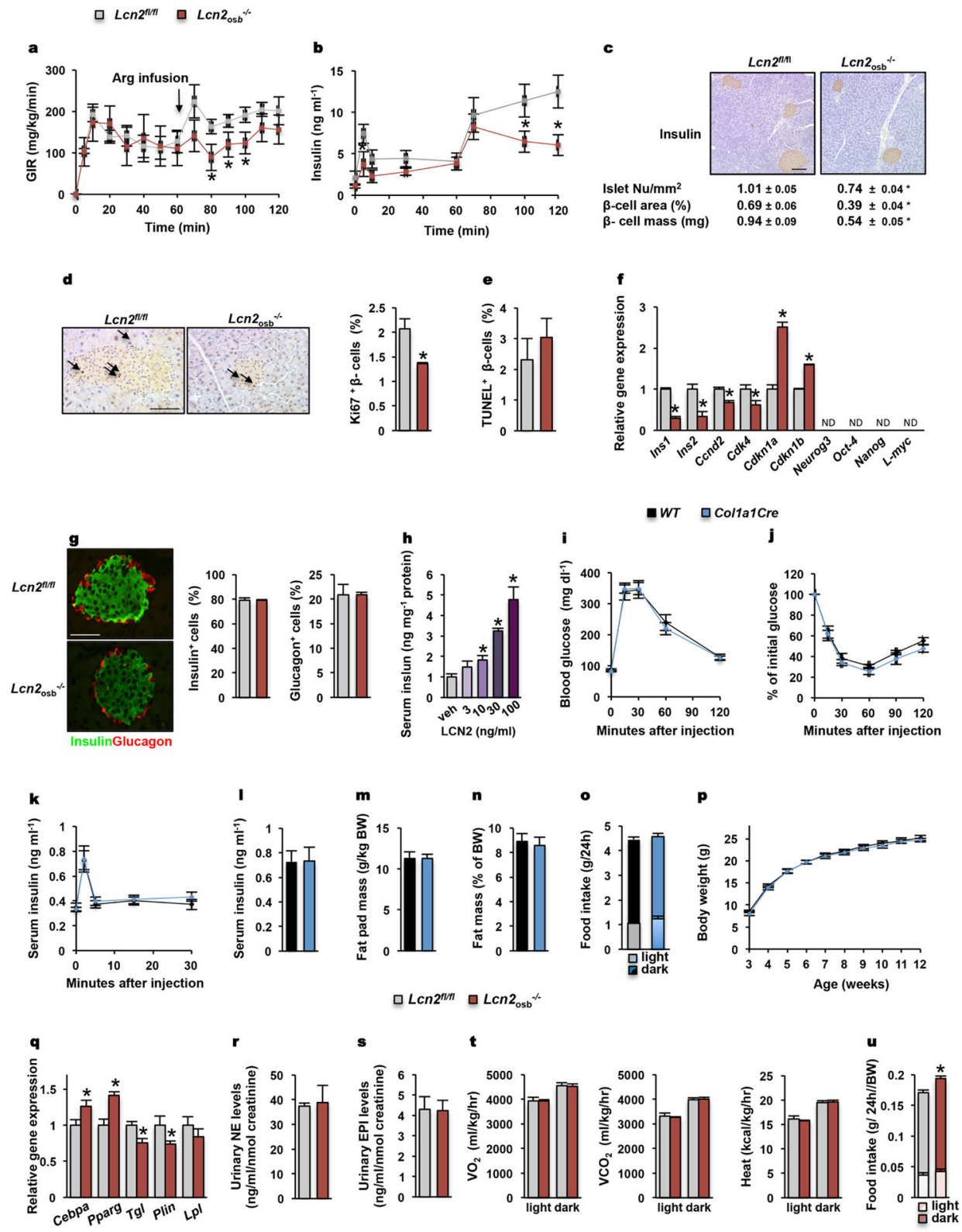

\section{Extended Data Figure 3. LCN2 regulates glucose homeostasis through its expression in} osteoblasts

a, b, Glucose infusion rate (a) and serum insulin levels (b) during hyperglycaemic clamp. c, Insulin staining and islet histomorphometry of pancreatic sections. d, Ki67 immunostaining and histomorphometric analysis of Ki67-immunoreactive cells in pancreatic islets (arrows indicate Ki67-positive cells). e, Histomorphometric analysis of TUNEL-positive $\beta$-cells in the pancreas. $\mathbf{f}$, Expression of insulin genes, cell cycle genes and $\beta$-cell dedifferentiation markers in pancreatic islets. g, Insulin and glucagon immunostaining and histomorphometric analysis of insulin- and glucagon-immunoreactive cells in pancreatic islets of $L c n 2_{\mathrm{osb}^{-1-}}$ mice and their $L c n 2^{f l / f l}$ littermates. $\mathbf{h}$, Insulin secretion in pancreatic islets treated with increasing doses of LCN2. i-p, Glucose tolerance (i), insulin tolerance (j) and glucose- 
stimulated insulin secretion (k), random-fed serum-insulin levels (l), fat pad mass (m), fat mass (n), food intake (o) and body weight (p) are not altered in Col1a1-Cre mice compared to their wild-type littermates. q, Expression levels of Cebpa, Pparg, Tgl (also known as Pnpla2), Plin1 (also known as Plin) and Lpl in white adipose tissue. $\mathbf{r}, \mathbf{s}$, Urinary levels of norepinephrine (r) and epinephrine (s) in $L c n 2_{\mathrm{osb}}{ }^{-1-}$ mice and $L c n 2^{f l / f l}$ littermates. $\mathbf{t}$, $\mathbf{u}$, Indirect calorimetry measurements $(\mathbf{t})$ and daily food intake normalized to body weight (u) in $L c n 2_{\mathrm{osb}^{-/-}}$mice and $L c n 2^{f l / f l}$ littermates. Scale bars, $200 \mu \mathrm{m}(\mathbf{c}), 100 \mu \mathrm{m}$ (d) and $50 \mu \mathrm{m}$ (g). Data are mean \pm s.e.m.; $n=5(\mathbf{a}, \mathbf{b}, \mathbf{e}, \mathbf{r}-\mathbf{t}), n=8(\mathbf{c}, \mathbf{d}, \mathbf{q}), n=7(\mathbf{i}-\mathbf{p}), n=3(\mathbf{g})$ and $n=$ 9 (u) mice per group. Results are representative of three independent experiments. $* P<0.05$ (Student's $t$-test).
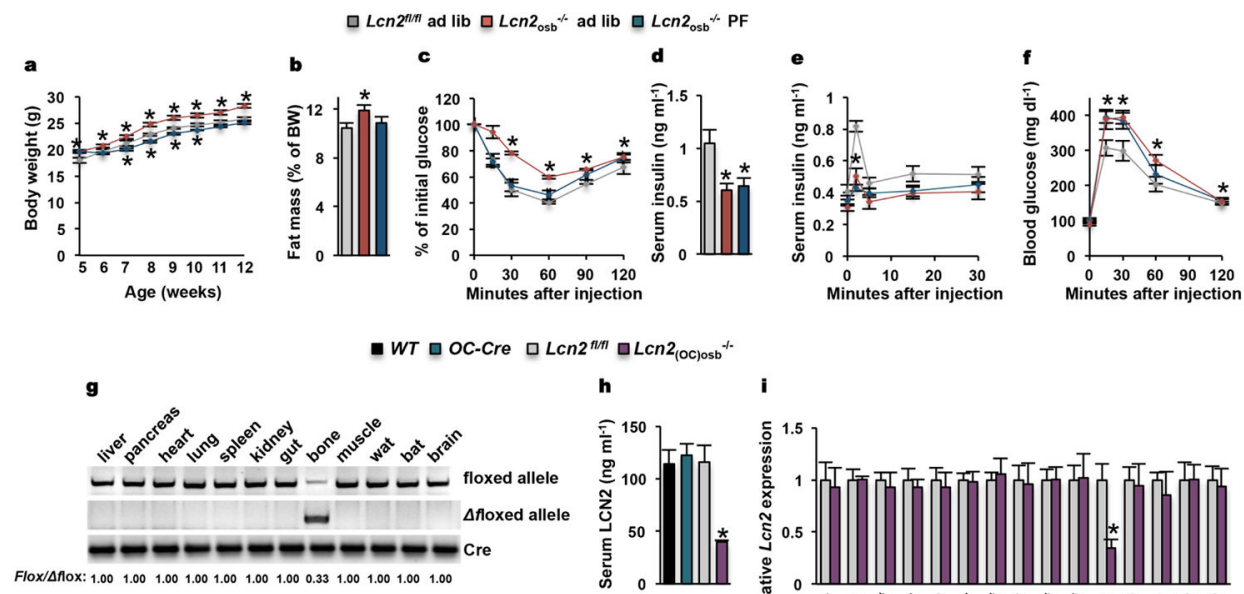

Flox/Lnox: 1.001 .001 .001 .001 .001 .001 .000 .331 .001 .001 .001 .00
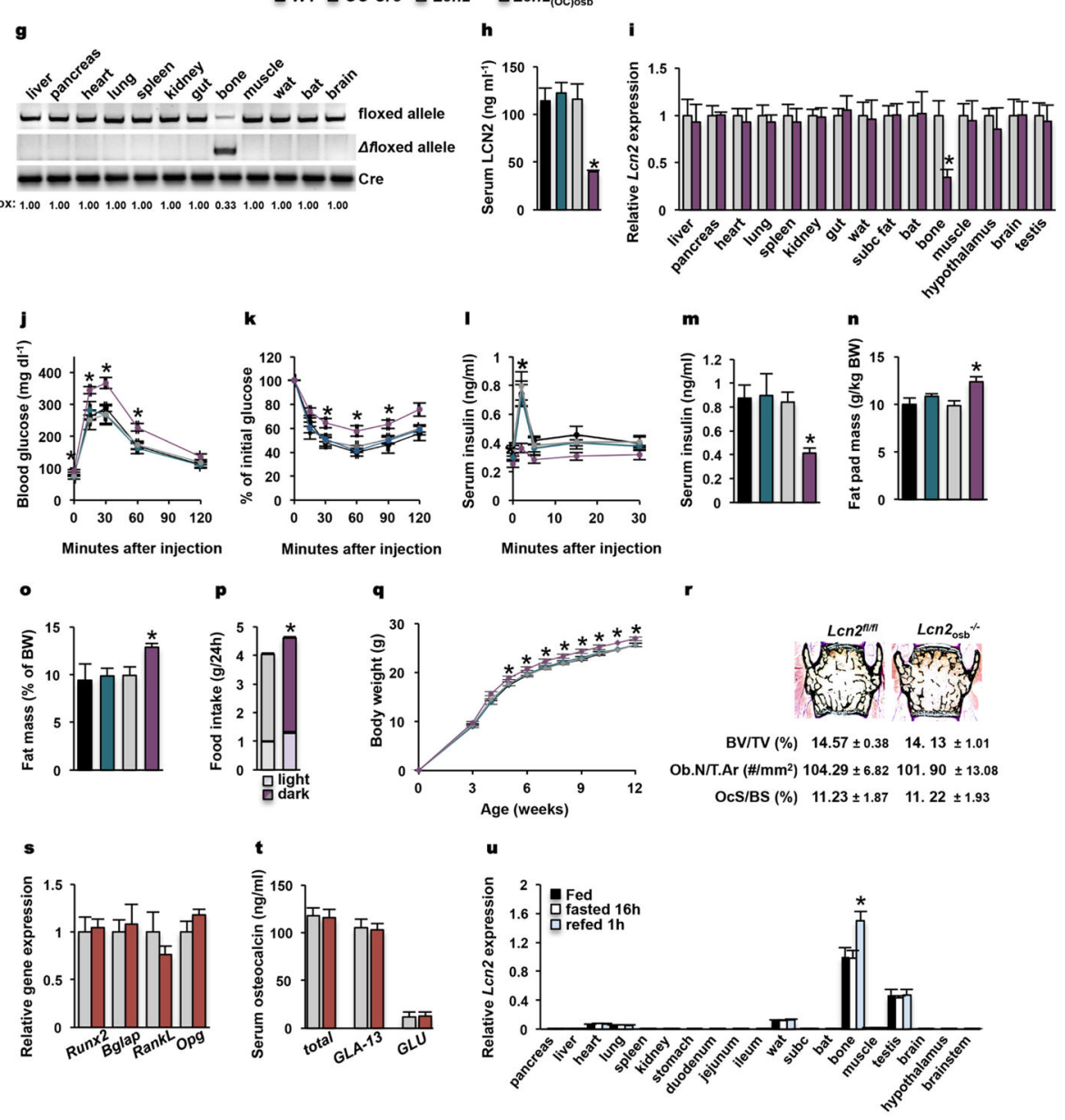

Nature. Author manuscript; available in PMC 2018 May 30. 
Extended Data Figure 4. The anorexigenic function of LCN2 influences fat mass, body weight and insulin sensitivity identically in $\operatorname{Lcn}_{\mathrm{osb}^{-/-}}$and $\operatorname{Lcn} 2_{(\mathrm{OC}) o s b^{-1-}}$ mice

a-f, Body weight (a), fat mass (b), insulin tolerance (c), serum insulin levels (d), glucosestimulated insulin secretion (e) and glucose tolerance (f) in pair-fed $L c n 2_{\mathrm{osb}^{-/}}$and $L c n 2^{f l / f 1}$ littermates. Data from Figs 2l, 2d, $1 \mathrm{~h}, 2 \mathrm{a}, 1 \mathrm{j}$ and $1 \mathrm{f}$, respectively, for fed $L c n 2_{\mathrm{osb}}{ }^{-/-}$mice are included for comparison. $g$, Detection of the Lcn2 floxed (primers a-b) and mutant allele, $\Delta$ flox, (primers c-d) in genomic DNA isolated from tissues of $L c n 2_{(\mathrm{oc}) \text { osb }}{ }^{-1-}$ mice. $\mathbf{h}, \mathbf{i}$, Serum levels of LCN2 (h) and tissue expression of $\operatorname{Lcn} 2$ (i) in $L c n 2_{(\mathrm{oc}) \text { osb }}{ }^{-1-}$ mice and their Lcn $2^{f l / f l}$ littermates. j-q, glucose tolerance $(\mathbf{j})$, insulin tolerance $(\mathbf{k})$, glucose-stimulated insulin secretion (l), random-fed serum-insulin levels (m), fat pad mass (n), fat mass (o), food intake (p) and body weight (q) in $L c n 2_{(\mathrm{oc}) \mathrm{osb}}{ }^{-/-}$mice and their $L c n 2^{f l / f l}$ littermates. $\mathbf{r}$, Histomorphometric analysis of bone mass and Von Kossa staining of vertebral sections. $\mathrm{BV} / \mathrm{TV}$, bone volume over tissue volume; Ob.N./T.Ar, osteoblast numbers per trabecular area; OcS/BS, osteoclast surface per bone surface. s, Expression levels of osteoblastogenic and osteoclastogenic genes in bone in $L c n 2_{\mathrm{Osb}}{ }^{-/-}$mice and their $L c n 2^{f l / f l}$ littermates. $\mathbf{t}$, Serum osteocalcin levels in $L c n 2_{\mathrm{osb}}{ }^{-/}$mice and their $L c n 2^{f l / f 1}$ littermates. u, Lcn2 expression levels in indicated tissues following fasting-refeeding of wild-type mice. Data are mean \pm s.e.m.; $n=6(\mathbf{a}-\mathbf{f}, \mathbf{r}), n=3(\mathbf{s}), n=10(\mathbf{t})$ and $n=5(\mathbf{u})$ mice per group; $n=3$

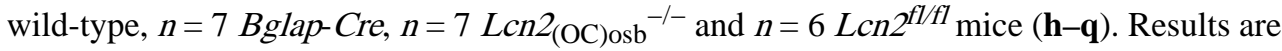
representative of three independent experiments. $* P<0.05$ (Student's $t$-test). 


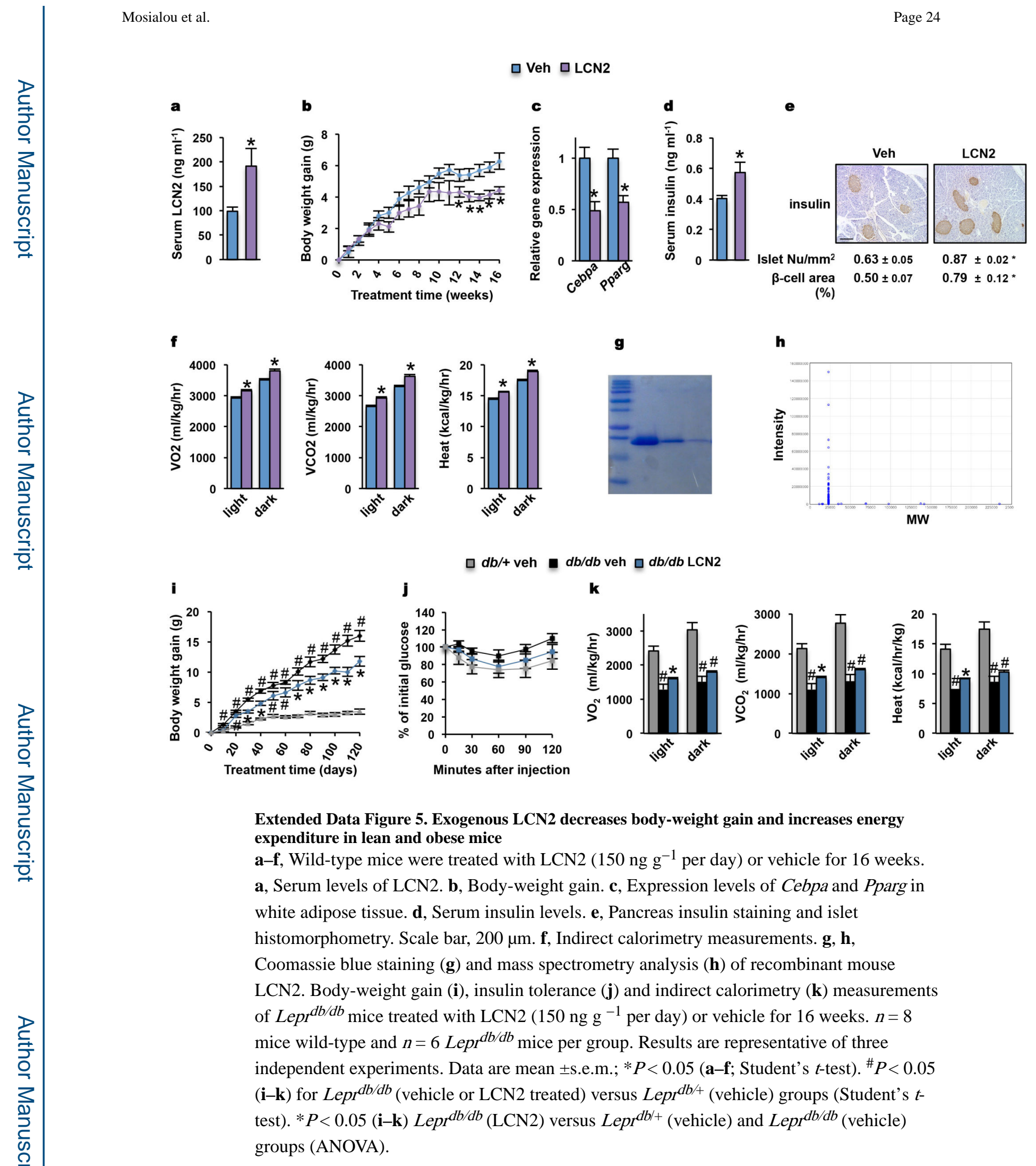

Nature. Author manuscript; available in PMC 2018 May 30. 

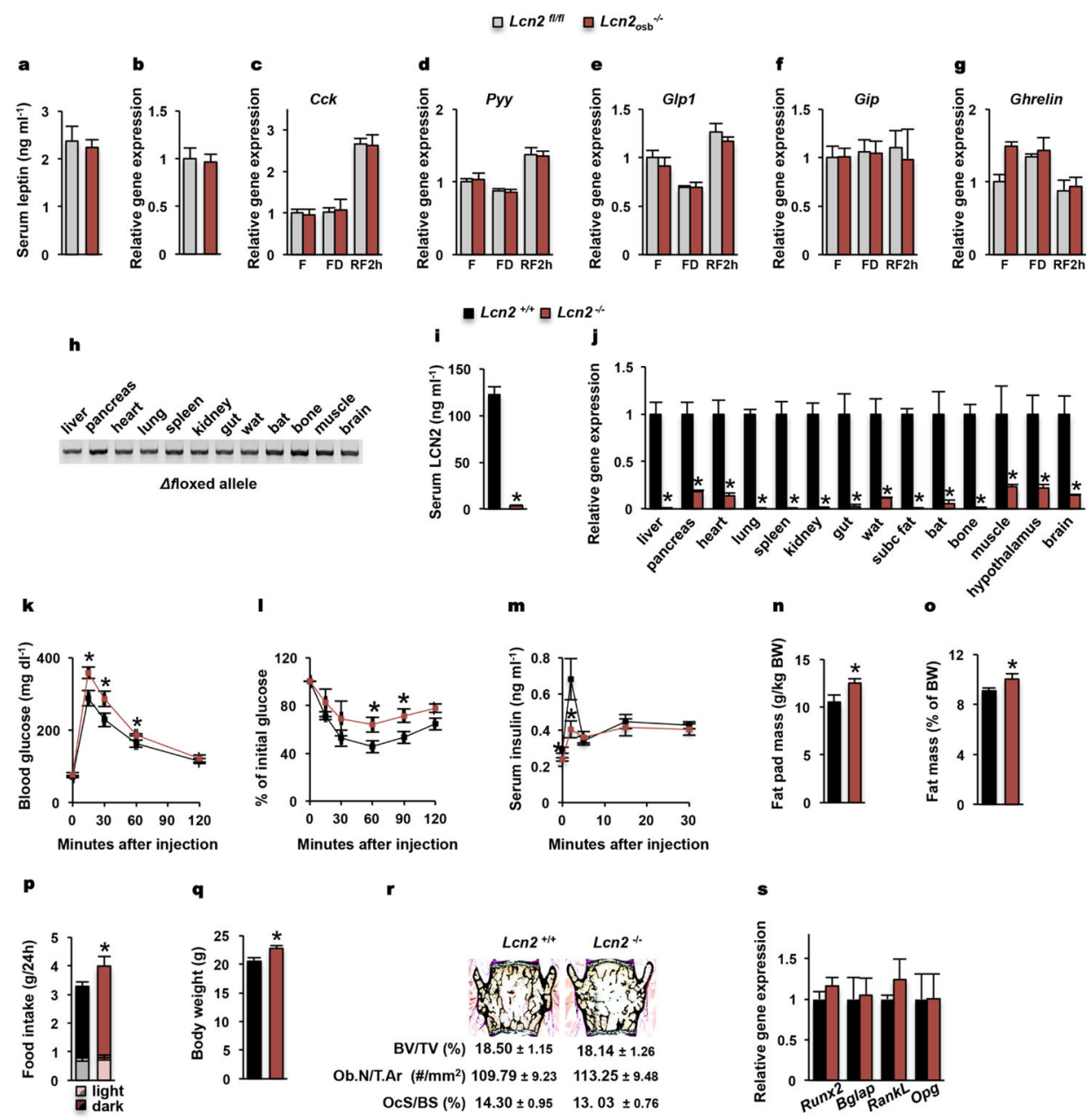

\begin{tabular}{lccc}
\cline { 2 - 4 } & \multicolumn{3}{c}{ LCN2 (pg/mg proteins) } \\
\cline { 2 - 4 } & LCN2 $\%$ & \multicolumn{1}{c}{ LCN2 $*$} & \multicolumn{1}{c}{ LCN2 ${ }^{*+}$} \\
\hline & veh & \multicolumn{1}{c}{ LCN2 } & veh \\
\hline serum $(\mathrm{ng} / \mathrm{ml})$ & $\mathbf{0 . 0 6} \pm 0.04$ & $107.05 \pm 6.46$ & $138.39 \pm 22.64$ \\
cortex & 0.00 & $5.67 \pm 0.50$ & $6.76 \pm 0.56$ \\
cerebellum & 0.00 & $8.44 \pm 0.63$ & $7.25 \pm 1.53$ \\
thalamus & 0.00 & $8.93 \pm 1.13$ & $6.32 \pm 0.47$ \\
brainstem & 0.00 & $16.96 \pm 1.18$ & $14.73 \pm 0.55$ \\
hypothalamus & 0.00 & $\mathbf{2 7 . 5 2} \pm 0.60$ & $\mathbf{2 8 . 1 6} \pm 1.13$ \\
\hline
\end{tabular}

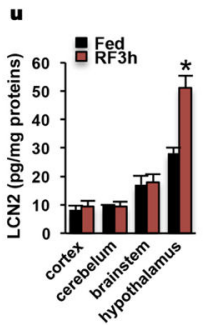

\begin{tabular}{lcc} 
& veh & \multicolumn{1}{c}{ LCN2 } \\
\hline \multicolumn{3}{c}{ LCN2 $(\mathrm{pg} / \mathrm{mg}$ proteins) } \\
\hline serum (ng/ml) & $0.06 \pm 0.07$ & $0.06 \pm 0.15$ \\
cortex & 0.00 & 0.00 \\
cerebellum & 0.00 & 0.00 \\
thalamus & 0.00 & 0.00 \\
brainstem & 0.00 & 0.00 \\
hypothalamus & 0.00 & $17.54 \pm 3.53$ \\
\hline
\end{tabular}

Extended Data Figure 6. Increased food intake, compromised glucose metabolism and normal bone mass in $\mathrm{Lcn}^{-/-}$mice

a, Serum levels of leptin in $L c n 2_{\mathrm{osb}}{ }^{-/-}$mice and their $L c n 2^{f l / f 1}$ littermates. b, Expression levels of leptin in white adipose tissue. $\mathbf{c - g}$, Expression levels of the gastrointestinal hormones that regulate appetite $C c k(\mathbf{c}), P y y(\mathbf{d})$, Glp1 (also known as Zglp1; e), Gip (f) and ghrelin ( Ghrl; g) under fed (F), 16-h fasted (FD) and re-fed (RF) (2 h after 16-h fasting) conditions for $L c n 2_{\mathrm{osb}}{ }^{-/-}$mice and their $L c n 2^{f l / f l}$ littermates. $\mathbf{h}$, Detection of the Lcn2 mutant allele, $\Delta$ flox, (primers c-d) in genomic DNA isolated from tissues of $L c n 2^{-/-}$mice. $\mathbf{i}$, $\mathbf{j}$, Serum levels of LCN2 (i) and tissue expression of $\operatorname{Lcn} 2(\mathbf{j})$ in $L c n 2^{-/-}$mice and their $L c n 2^{+/+}$littermates. $\mathbf{k}-\mathbf{s}$, Analysis of $L c n 2^{-/-}$mice and their $L c n 2^{+/+}$littermates. k, Glucose 
tolerance test. I, Insulin tolerance test. m, Glucose-stimulated insulin secretion. n, Fat pad mass. o, Fat mass. p, Food intake. q, Body weight. r, Bone histomorphometric analysis. s, Expression levels of osteoblastogenic and osteoclastogenic genes in bone. $\mathbf{t}, \mathbf{u}, \mathrm{LCN} 2$ crosses the blood-brain barrier to regulate food intake. $\mathbf{t}, \mathrm{LCN} 2$ levels in the brain and serum of $\mathrm{Lcn}^{-1-}$ and wild-type littermates $2 \mathrm{~h}$ after i.p. administration of LCN2. u, LCN2 levels in the brain of wild-type mice $3 \mathrm{~h}$ after refeeding. $\mathbf{v}$, LCN2 levels in the brain and serum of Lcn $2^{-1-}$ mice following ICV administration of $0.02 \mathrm{ng} \mathrm{h}^{-1} \mathrm{LCN} 2$ or vehicle for 8 days. Data are mean \pm s.e.m.; $n=10(\mathbf{a}, \mathbf{b}, \mathbf{i}), n=5(\mathbf{c}-\mathbf{g}, \mathbf{k}, \mathbf{l}, \mathbf{p}, \mathbf{r}, \mathbf{s}), n=7(\mathbf{m}-\mathbf{o}, \mathbf{q}), n=4(\mathbf{j}, \mathbf{t})$ and $n=3(\mathbf{u}, \mathbf{v})$ mice per group. Results are representative of three independent experiments. $* P<0.05$ (Student's $t$-test).
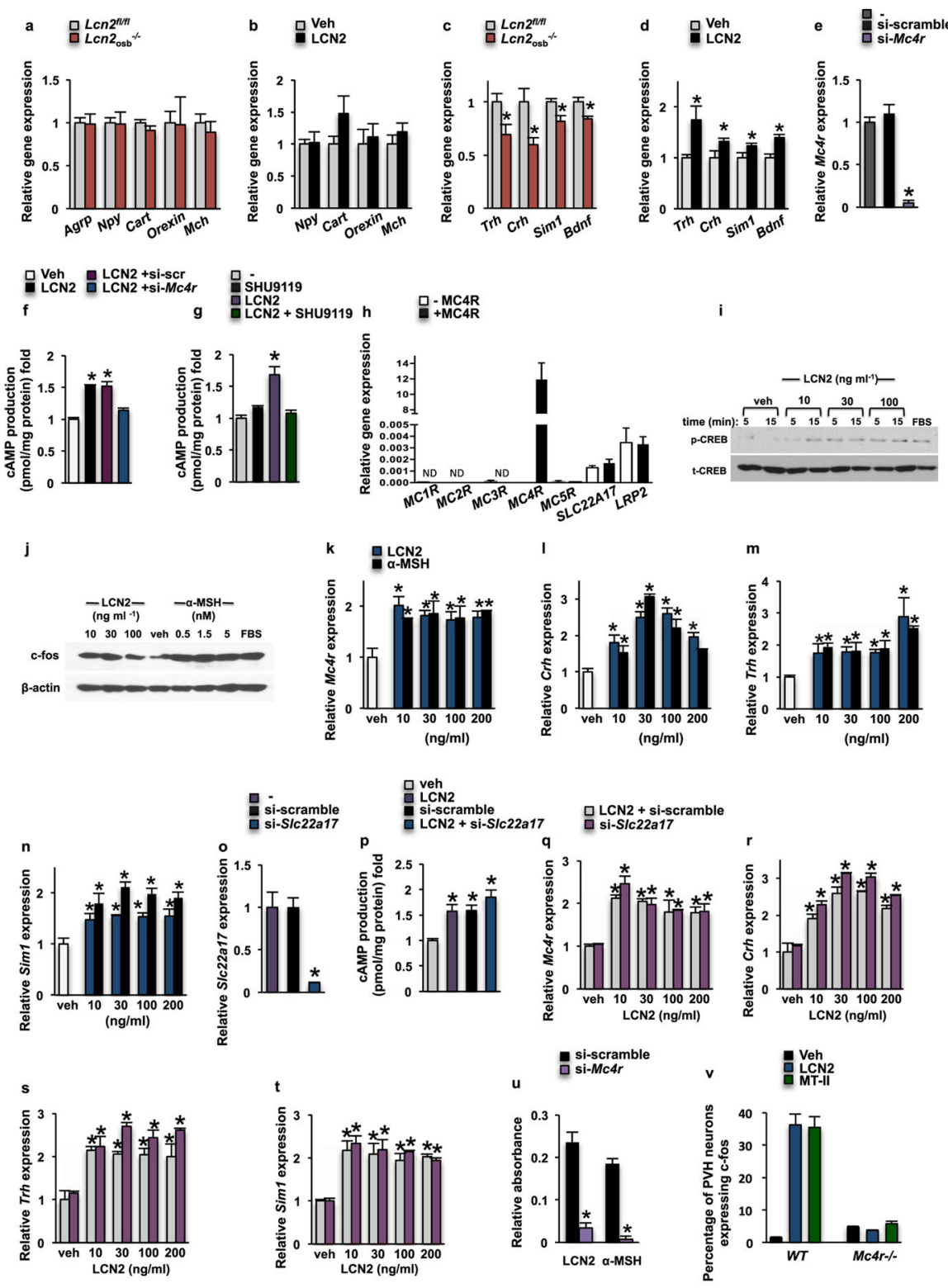
Extended Data Figure 7. MC4R, but not SLC22A17, is required for the stimulation of cAMP activity and anorexigenic gene expression induced by LCN2

a-d, Expression levels of neuropeptides regulating appetite in the hypothalamus of $L c n 2^{f l / f 1}$ and $L c n 2_{\mathrm{Osb}^{-1-}}$ mice (a, c) and wild-type mice injected daily i.p. with LCN2 (150 ng g ${ }^{-1}$ per day) or vehicle for 16 weeks (b, d). e, o, $M c 4 r(\mathbf{e})$ or $S l c 22 a 17(\mathbf{o})$ expression levels in GT1-7 hypothalamic cells following transfection with $M c 4 r$ or Slc22a17 siRNA. siscramble, Scramble siRNA. f, g, p, cAMP production in GT1-7 cells treated with LCN2 following pretreatment with the SHU9119 inhibitor (g) or silencing of $\operatorname{Mc} 4 r(\mathbf{f})$ or $\operatorname{Slc22a17}$ (p) expression. $\mathbf{h}$, Expression levels of melanocortin receptors and LCN2 receptors in HEK293T cells transfected with an $M C 4 R$ expression vector or empty vector. ND, not detected. i, j, Western blot analysis of CREB phosphorylation (i) and FOS induction (j) in GT1-7 cells treated with LCN2, vehicle or a-MSH. k-t, Expression levels of $M c 4 r$ and targets in GT1-7 cells treated with LCN2 or a-MSH for $4 \mathrm{~h}(\mathbf{k}-\mathbf{n})$ and after silencing of Slc22a17 (q-t). u, Binding of biotinylated LCN2 and a-MSH in GT1-7 cells transiently transfected with $M c 4 r$ siRNA or scramble siRNA. v, Quantification of Fos-expressing neurons in the PVH of wild-type and $\mathrm{Mc} \mathrm{r}^{-/-}$mice injected with LCN2 or MT-II. Data are mean \pm s.e.m. of triplicates. $n=9$ (a) and $n=7$ (b-d) mice per group. Results are representative of three independent experiments. $* P<0.05$ (Student's $t$-test). 


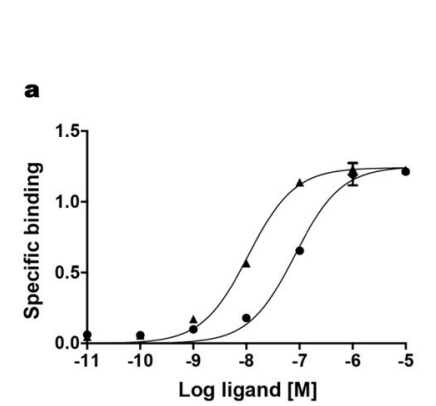

$\bullet$ LCN2 $\leftarrow$ a-MSH $\neg$ AgRP $\leftarrow$ Leptin
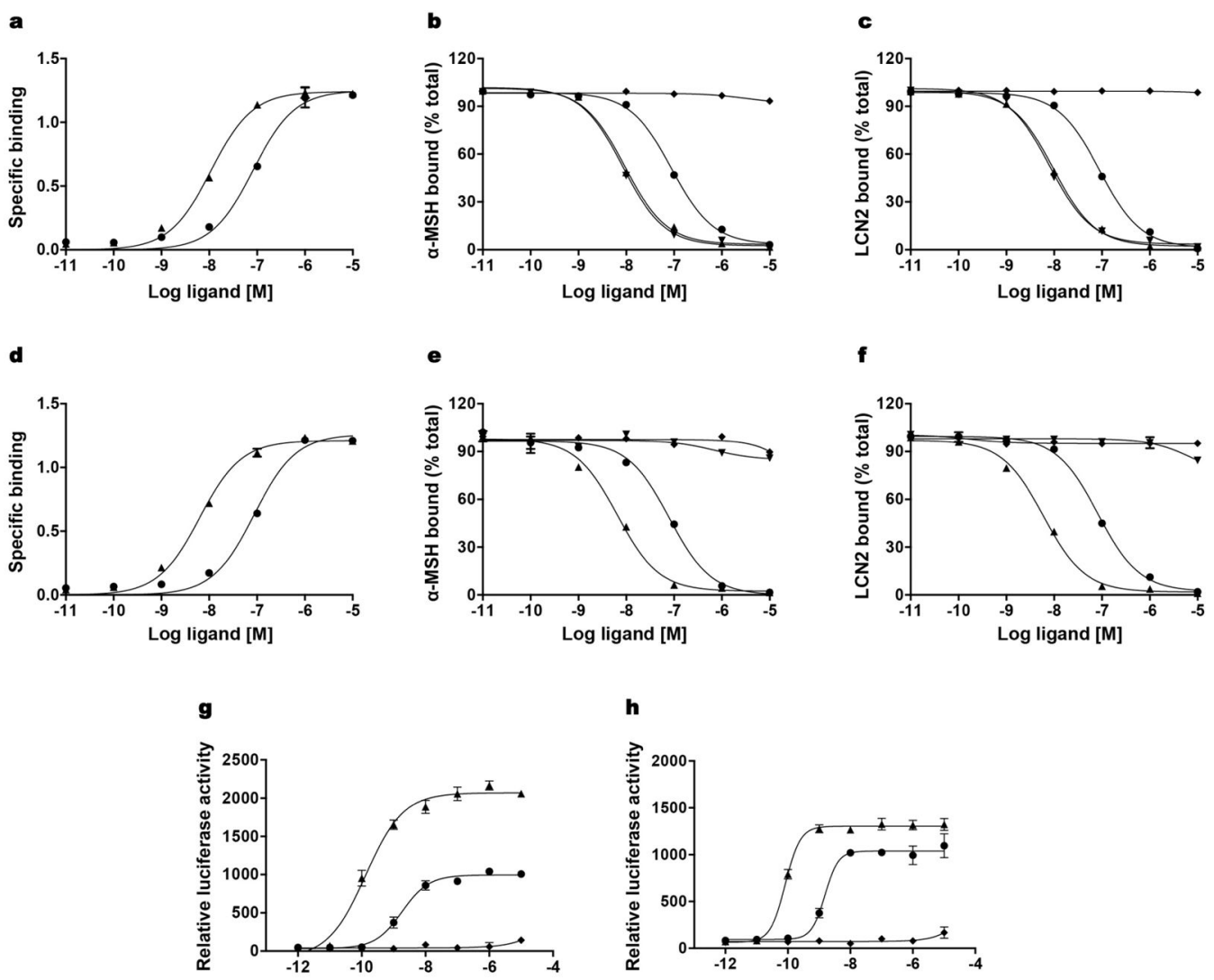

$\mathbf{i}$

\begin{tabular}{|c|c|c|c|c|c|c|c|c|c|c|}
\hline & \multirow{2}{*}{\multicolumn{2}{|c|}{$E C_{50}(\mathrm{nM})$}} & \multirow{2}{*}{\multicolumn{2}{|c|}{$K_{\mathrm{d}}(\mathrm{nM})$}} & \multicolumn{6}{|c|}{$K_{\mathrm{i}}(\mathrm{nM})$} \\
\hline & & & & & \multicolumn{3}{|c|}{ bio-a-MSH binding } & \multicolumn{3}{|c|}{ bio-LCN2 binding } \\
\hline & LCN2 & $\alpha-M S H$ & LCN2 & $\alpha-M S H$ & $\alpha-M S H$ & LCN2 & AGRP & $\alpha-M S H$ & LCN2 & AGRP \\
\hline MC4R & $1.41 \pm 0.25$ & $0.09 \pm 0.01$ & $51.39 \pm 4.78$ & $11.93 \pm 1.23$ & $14.75 \pm 1.04$ & $46.34 \pm 1.11$ & $9.04 \pm 1.14$ & $12.63 \pm 1.10$ & $54.22 \pm 1.08$ & $8.82 \pm 1.15$ \\
\hline MC3R & $1.83 \pm 0.08$ & $0.13 \pm 0.00$ & $82.13 \pm 12.14$ & $10.81 \pm 1.06$ & $9.65 \pm 1.07$ & $89.32 \pm 1.05$ & $8.88 \pm 1.09$ & $9.96 \pm 1.04$ & $89.97 \pm 1.05$ & $8.37 \pm 1.06$ \\
\hline MC1R & $1.52 \pm 0.14$ & $0.08 \pm 0.00$ & $86.96 \pm 9.72$ & $6.3 \pm 0.56$ & $6.9 \pm 1.08$ & $79.54 \pm 1.11$ & $682 \pm 5.08$ & $6.17 \pm 1.07$ & $86.24 \pm 1.04$ & $3457 \pm 34.10$ \\
\hline
\end{tabular}

Extended Data Figure 8. Binding affinity and activation potency of LCN2 on MC3R and MC1R a-f, Saturation (a, d) and competition binding $(\mathbf{b}, \mathbf{c}, \mathbf{e}, \mathbf{f})$ assay curves of LCN2 and a-MSH in HEK293T cells transfected with $M C 3 R(\mathbf{a}-\mathbf{c})$ or $M C 1 R(\mathbf{d}-\mathbf{f})$. Displacement of biotinylated a-MSH (b, e) or biotinylated LCN2 $(\mathbf{c}, \mathbf{f})$ by the indicated proteins. $\mathbf{g}, \mathbf{h}, \mathrm{cAMP}$ production in HEK293T cells transfected with $M C 3 R(\mathbf{g})$ or $M C 1 R(\mathbf{h})$ along with a cAMP/ luciferase reporter and treated for $15 \mathrm{~min}$ as indicated. Results are representative of three independent experiments. Data are mean \pm s.e.m.; i, $\mathrm{EC}_{50}, K_{d}$ and $K_{i}$ of LCN2, a-MSH and AGRP on melanocortin receptors expressed in HEK293T cells. 

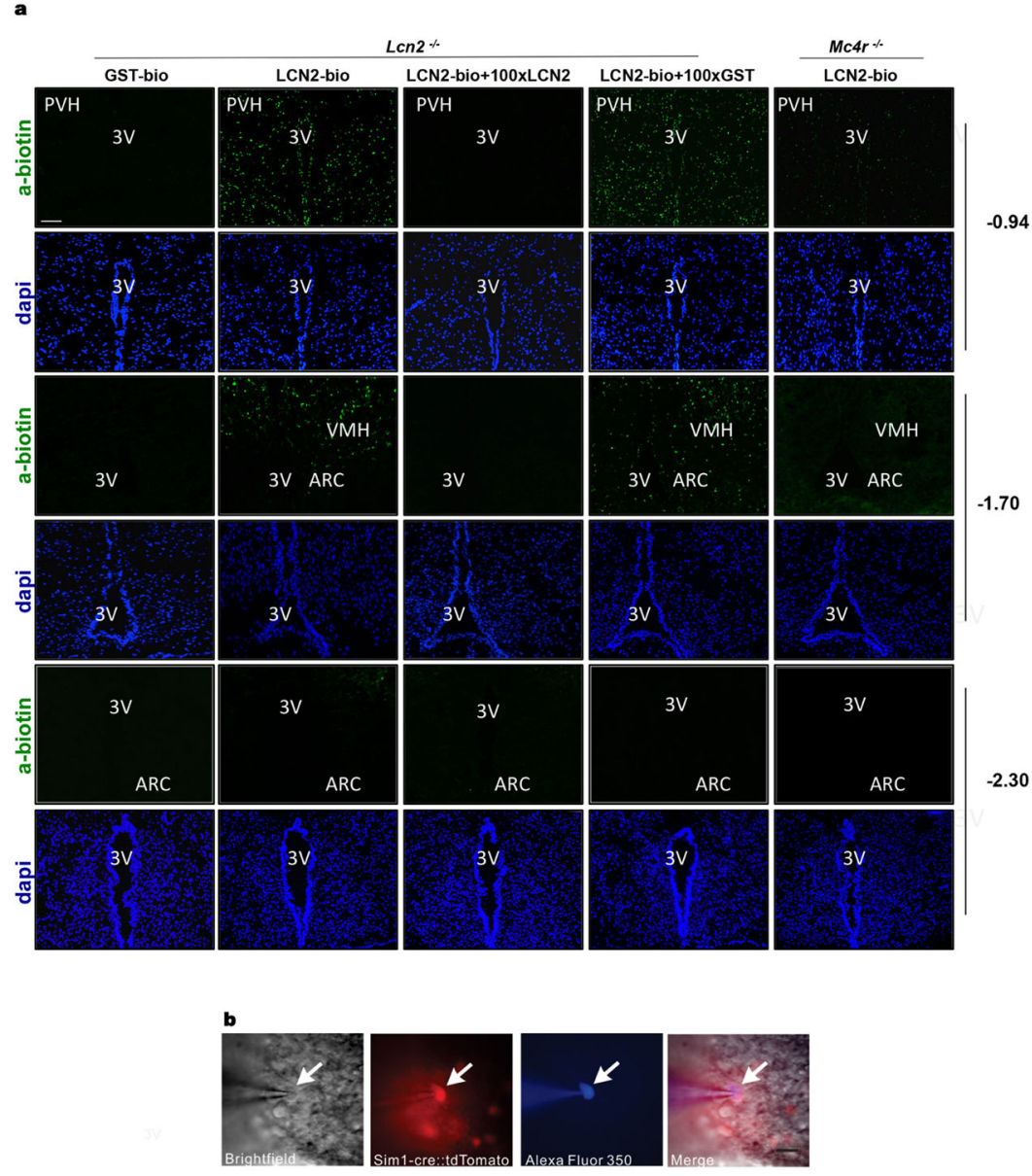

c
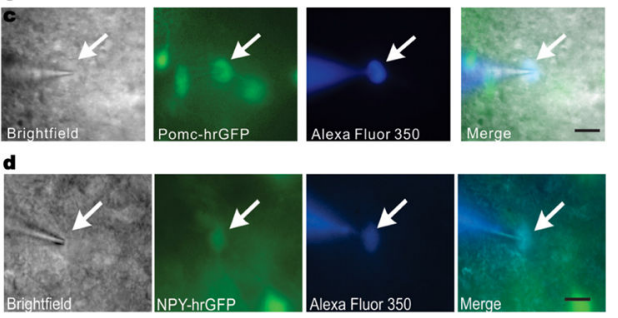

Extended Data Figure 9. Binding and activation of PVH neurons by LCN2

a, Binding of biotinylated LCN2 to PVH and VMH neurons, but not neurons in the arcuate nucleus (ARC) in hypothalamic sections of $\mathrm{Lcn}^{-/-}$and $\mathrm{Mc}^{-1-} \mathrm{r}^{--}$mice. Competition with unlabelled LCN2 or GST. b-d, Bright-field images of a targeted (as indicated by the arrows) neurons. b, A Sim-1 neuron from a Sim-1 cre::tdTomato mouse. c, A Pomc neuron from $P o m c$-hrGFP mouse. d, A $N p y$ neuron from $N p y$-hrGFP mouse. The same neuron is shown in red (Alexa Fluor 594, tdTomato), green (FITC, hrGFP) and blue (Alexa Fluor 350, DAPI), as well the merged image. Scale bars, $100 \mu \mathrm{m}$ (a) and $50 \mu \mathrm{m}$ (b-d). 

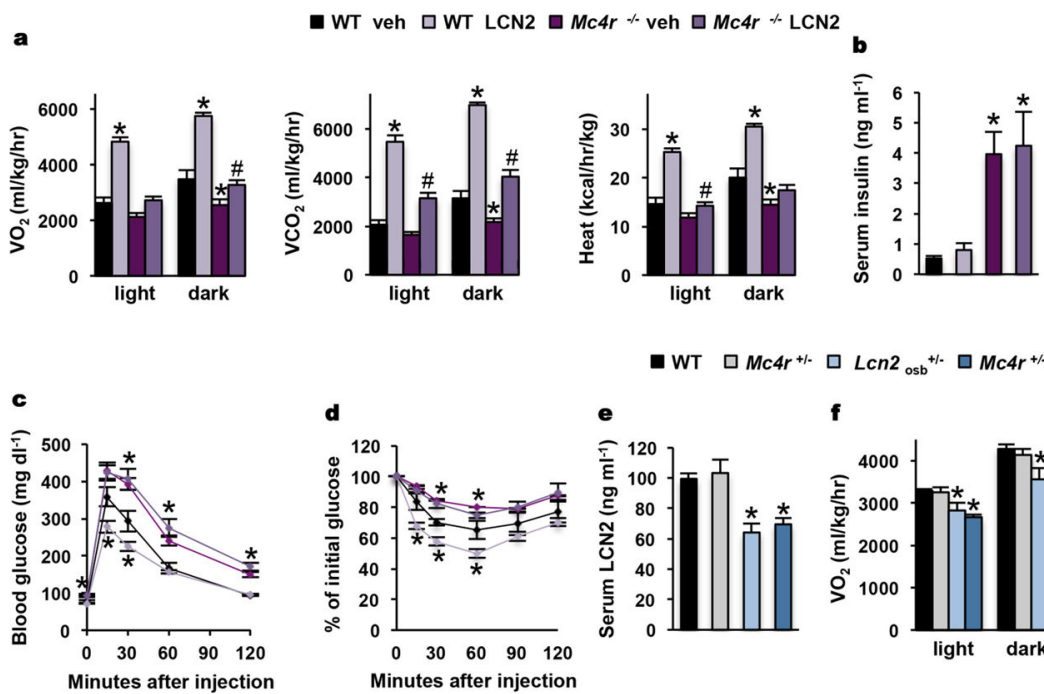

- WT $\square M c 4 r^{+/ .} \square L C n 2 \mathrm{osb}^{+/-} \square M c 4 r^{+/}::$LCn2 $\mathrm{osb}^{+/-}$
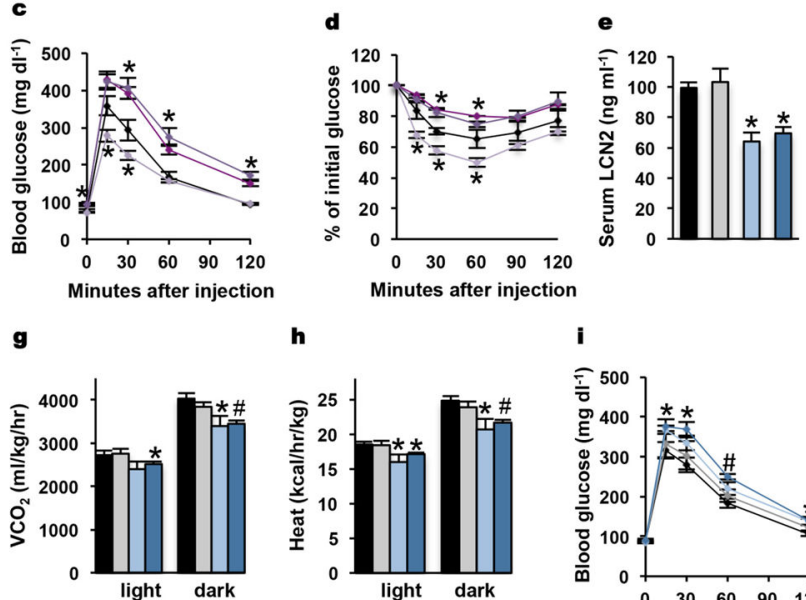

$\mathbf{f}$
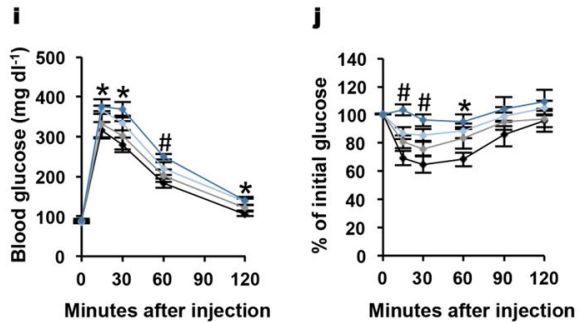

$\mathbf{k}$

$\mathbf{I}$

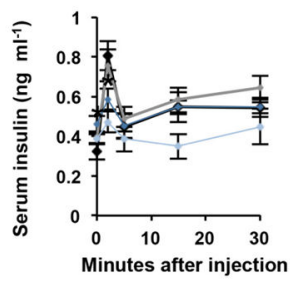

\begin{tabular}{lcccc}
\hline MC4R results & Sex & Age & BMI $\left(\mathrm{Kg} / \mathrm{m}^{2}\right)$ & LCN2 $(\mathrm{ng} / \mathrm{ml})$ \\
\hline Normal & f & 18.0 & 35.3 & 168.207 \\
Normal & $\mathrm{m}$ & 16.9 & 52.9 & 60.616 \\
Normal & $\mathrm{m}$ & 19.3 & 38.4 & 52.957 \\
Normal & f & 17.2 & 71.3 & 63.658 \\
Normal & f & 16.6 & 55.8 & 78.465 \\
Normal & f & 10.4 & 37.1 & 55.056 \\
p.Phe202Leu & m & 19.0 & 46.0 & 358.713 \\
p.Cys271Arg & m & 17.3 & 56.9 & 35.927 \\
p.Asp146His & f & 17.7 & 43.4 & 183.602 \\
p.Leu139CysfsTer22 & f & 16.6 & 36.1 & 46.553 \\
p.lle251TrpfsTer34 & f & 16.8 & 46.9 & 136.504 \\
p.lle251TrpfsTer34 & f & 10.1 & 51.0 & 82.991 \\
\hline
\end{tabular}

Extended Data Figure 10. MC4R is required for the improvement in glucose metabolism and energy expenditure by LCN2

a-d, $M c 4 r^{-1-}$ and wild-type littermates were treated with LCN2 $(150 \mathrm{ng} / \mathrm{g} /$ day $)$ or vehicle for 8 weeks. a, Indirect calorimetry measurements. b, Serum insulin levels. c, Glucose tolerance test. d, Insulin tolerance test. $\mathbf{e}-\mathbf{k}$, Serum levels of LCN2 (e), indirect calorimetry measurements $(\mathbf{f}-\mathbf{h})$, glucose tolerance test $(\mathbf{i})$, insulin tolerance test $(\mathbf{j})$ and glucose-

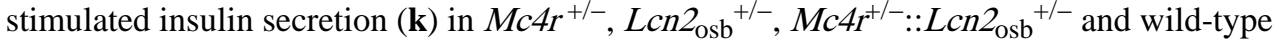
littermates. Data are mean \pm s.e.m.; $n=5$ wild-type and $n=7 M c 4 r^{-1-}$ mice (a-d). l, LCN2 plasma levels in patients with mutated and normal $M C 4 R$ sequences. $n=6$ wild-type, $M c 4 r$ ${ }^{+/-}$and $M c 4 r^{+/-}:: L c n 2_{\mathrm{osb}}{ }^{+/-}$mice and $n=5 L c n 2_{\mathrm{osb}^{+/-}}$mice (e-k). Results are representative of three independent experiments. $* P<0.05$ indicated genotypes or treatments versus wildtype mice (Student's $t$-test). ${ }^{\#} P<0.05$ when comparing either $M c 4 r^{-1-}$ (vehicle-treated) and $M c 4 r^{+/-}$(LCN2-treated) groups (a) or $M c 4 r^{+/-}:: L c n 2_{\mathrm{osb}^{+/-}}$mice versus wild-type, $M c 4 \mathrm{r}^{+/-}$ and $L c n 2_{\mathrm{osb}^{+-}}$mice (f-k) (ANOVA). 


\section{Supplementary Material}

Refer to Web version on PubMed Central for supplementary material.

\section{Acknowledgments}

The authors are grateful to A. Tarasenco for technical assistance, the Histology and Metabolic Unit facility of the Diabetes and Endocrinology Research Center (DERC, NIDDK DK063608-07), R. Tomaino of the Taplin Mass Spectrometry Facility, Harvard Medical School and the Albert Einstein DRTC Animal Physiology Core (NIDDK DK20541). This work was supported by the National Institutes of Health R01AR054447, P01AG032959 and R01AR055931 to S.K., R01DK100699 to K.W.W., R01DK52431 to R.L.L. and W.C., P30DK26687 to R.L.L. and W.C., P30DK063608 to R.L.L. and W.C., NOVO Nordisk to S.K and by the T32 Training Grant DK07328 to S.S.

\section{References}

1. Friedman JM, Halaas JL. Leptin and the regulation of body weight in mammals. Nature. 1998; 395:763-770. [PubMed: 9796811]

2. Brüning JC, et al. Role of brain insulin receptor in control of body weight and reproduction. Science. 2000; 289:2122-2125. [PubMed: 11000114]

3. Drucker DJ. The biology of incretin hormones. Cell Metab. 2006; 3:153-165. [PubMed: 16517403]

4. Choudhury AI, et al. The role of insulin receptor substrate 2 in hypothalamic and $\beta$ cell function. $\mathrm{J}$ Clin Invest. 2005; 115:940-950. [PubMed: 15841180]

5. Batterham RL, et al. Critical role for peptide YY in protein-mediated satiation and body-weight regulation. Cell Metab. 2006; 4:223-233. [PubMed: 16950139]

6. Coll AP, Farooqi IS, O'Rahilly S. The hormonal control of food intake. Cell. 2007; 129:251-262. [PubMed: 17448988]

7. Lee NK, et al. Endocrine regulation of energy metabolism by the skeleton. Cell. 2007; 130:456-469. [PubMed: 17693256]

8. Ferron M, et al. Insulin signaling in osteoblasts integrates bone remodeling and energy metabolism. Cell. 2010; 142:296-308. [PubMed: 20655470]

9. Fulzele K, et al. Insulin receptor signaling in osteoblasts regulates postnatal bone acquisition and body composition. Cell. 2010; 142:309-319. [PubMed: 20655471]

10. Rached MT, et al. FoxO1 expression in osteoblasts regulates glucose homeostasis through regulation of osteocalcin in mice. J Clin Invest. 2010; 120:357-368. [PubMed: 20038793]

11. Bhattacharyya N, Chong WH, Gafni RI, Collins MT. Fibroblast growth factor 23: state of the field and future directions. Trends Endocrinol Metab. 2012; 23:610-618. [PubMed: 22921867]

12. Yoshikawa $Y$, et al. Genetic evidence points to an osteocalcin-independent influence of osteoblasts on energy metabolism. J Bone Miner Res. 2011; 26:2012-2025. [PubMed: 21557308]

13. Huszar D, et al. Targeted disruption of the melanocortin-4 receptor results in obesity in mice. Cell. 1997; 88:131-141. [PubMed: 9019399]

14. Butler AA, Cone RD. The melanocortin receptors: lessons from knockout models. Neuropeptides. 2002; 36:77-84. [PubMed: 12359499]

15. Balthasar N, et al. Divergence of melanocortin pathways in the control of food intake and energy expenditure. Cell. 2005; 123:493-505. [PubMed: 16269339]

16. Liu H, et al. Transgenic mice expressing green fluorescent protein under the control of the melanocortin-4 receptor promoter. J Neurosci. 2003; 23:7143-7154. [PubMed: 12904474]

17. Ste Marie L, Miura GI, Marsh DJ, Yagaloff K, Palmiter RD. A metabolic defect promotes obesity in mice lacking melanocortin-4 receptors. Proc Natl Acad Sci USA. 2000; 97:12339-12344. [PubMed: 11027312]

18. Coll AP, Farooqi IS, Challis BG, Yeo GS, O'Rahilly S. Proopiomelanocortin and energy balance: insights from human and murine genetics. J Clin Endocrinol Metab. 2004; 89:2557-2562.

[PubMed: 15181023] 
19. Hinney A, et al. Prevalence, spectrum, and functional characterization of melanocortin-4 receptor gene mutations in a representative population-based sample and obese adults from Germany. J Clin Endocrinol Metab. 2006; 91:1761-1769. [PubMed: 16492696]

20. Larsen LH, et al. Prevalence of mutations and functional analyses of melanocortin 4 receptor variants identified among 750 men with juvenile-onset obesity. J Clin Endocrinol Metab. 2005; 90:219-224. [PubMed: 15486053]

21. Nix MA, et al. Molecular and functional analysis of human $\beta$-defensin 3 action at melanocortin receptors. Chem Biol. 2013; 20:784-795. [PubMed: 23790489]

22. Yan QW, et al. The adipokine lipocalin 2 is regulated by obesity and promotes insulin resistance. Diabetes. 2007; 56:2533-2540. [PubMed: 17639021]

23. Lin Y, et al. Hyperglycemia-induced production of acute phase reactants in adipose tissue. J Biol Chem. 2001; 276:42077-42083. [PubMed: 11546817]

24. Soukas A, Cohen P, Socci ND, Friedman JM. Leptin-specific patterns of gene expression in white adipose tissue. Genes Dev. 2000; 14:963-980. [PubMed: 10783168]

25. Dacquin R, Starbuck M, Schinke T, Karsenty G. Mouse a1(I)-collagen promoter is the best known promoter to drive efficient Cre recombinase expression in osteoblast. Dev Dyn. 2002; 224:245251. [PubMed: 12112477]

26. Kalajzic Z, et al. Directing the expression of a green fluorescent protein transgene in differentiated osteoblasts: comparison between rat type I collagen and rat osteocalcin promoters. Bone. 2002; 31:654-660. [PubMed: 12531558]

27. Qiang G, et al. Lipodystrophy and severe metabolic dysfunction in mice with adipose tissuespecific insulin receptor ablation. Mol Metab. 2016; 5:480-490. [PubMed: 27408774]

28. Scheller EL, Cawthorn WP, Burr AA, Horowitz MC, MacDougald OA. Marrow adipose tissue: trimming the fat. Trends Endocrinol Metab. 2016; 27:392-403. [PubMed: 27094502]

29. Zhang M, et al. Osteoblast-specific knockout of the insulin-like growth factor (IGF) receptor gene reveals an essential role of IGF signaling in bone matrix mineralization. J Biol Chem. 2002; 277:44005-44012. [PubMed: 12215457]

30. Coleman DL. Obese and diabetes: two mutant genes causing diabetes-obesity syndromes in mice. Diabetologia. 1978; 14:141-148. [PubMed: 350680]

31. Kelly E, Bailey CP, Henderson G. Agonist-selective mechanisms of GPCR desensitization. Br J Pharmacol. 2008; 153(Suppl 1):S379-S388. [PubMed: 18059321]

32. Gainetdinov RR, Premont RT, Bohn LM, Lefkowitz RJ, Caron MG. Desensitization of G proteincoupled receptors and neuronal functions. Annu Rev Neurosci. 2004; 27:107-144. [PubMed: 15217328]

33. Garfield AS, et al. A neural basis for melanocortin-4 receptor-regulated appetite. Nat Neurosci. 2015; 18:863-871. [PubMed: 25915476]

34. Myers MG Jr, Olson DP. Central nervous system control of metabolism. Nature. 2012; 491:357363. [PubMed: 23151578]

35. Cone RD. Anatomy and regulation of the central melanocortin system. Nat Neurosci. 2005; 8:571578. [PubMed: 15856065]

36. Berglund ED, et al. Melanocortin 4 receptors in autonomic neurons regulate thermogenesis and glycemia. Nat Neurosci. 2014; 17:911-913. [PubMed: 24908101]

37. Kublaoui BM, Holder JL Jr, Gemelli T, Zinn AR. Sim1 haploinsufficiency impairs melanocortinmediated anorexia and activation of paraventricular nucleus neurons. Mol Endocrinol. 2006; 20:2483-2492. [PubMed: 16728530]

38. Law IK, et al. Lipocalin-2 deficiency attenuates insulin resistance associated with aging and obesity. Diabetes. 2010; 59:872-882. [PubMed: 20068130]

39. Guo H, et al. Lipocalin-2 deficiency impairs thermogenesis and potentiates diet-induced insulin resistance in mice. Diabetes. 2010; 59:1376-1385. [PubMed: 20332347]

40. Eguchi J, et al. Transcriptional control of adipose lipid handling by IRF4. Cell Metab. 2011; 13:249-259. [PubMed: 21356515]

41. Paragas N, et al. The Ngal reporter mouse detects the response of the kidney to injury in real time. Nat Med. 2011; 17:216-222. [PubMed: 21240264] 
42. Parton LE, et al. Glucose sensing by POMC neurons regulates glucose homeostasis and is impaired in obesity. Nature. 2007; 449:228-232. [PubMed: 17728716]

43. van den Pol AN, et al. Neuromedin B and gastrin-releasing peptide excite arcuate nucleus neuropeptide $\mathrm{Y}$ neurons in a novel transgenic mouse expressing strong Renilla green fluorescent protein in NPY neurons. J Neurosci. 2009; 29:4622-4639. [PubMed: 19357287]

44. DeFronzo RA, Tobin JD, Andres R. Glucose clamp technique: a method for quantifying insulin secretion and resistance. Am J Physiol. 1979; 237:E214-E223. [PubMed: 382871]

45. Kode A, et al. FOXO1 orchestrates the bone-suppressing function of gut-derived serotonin. J Clin Invest. 2012; 122:3490-3503. [PubMed: 22945629]

46. Sohn JW, et al. Serotonin $2 \mathrm{C}$ receptor activates a distinct population of arcuate proopiomelanocortin neurons via TRPC channels. Neuron. 2011; 71:488-497. [PubMed: 21835345]

47. Williams KW, et al. Xbp1s in Pomc neurons connects ER stress with energy balance and glucose homeostasis. Cell Metab. 2014; 20:471-482. [PubMed: 25017942]

48. Mellon PL, et al. Immortalization of hypothalamic GnRH neurons by genetically targeted tumorigenesis. Neuron. 1990; 5:1-10. [PubMed: 2196069]

49. Ashburner M, et al. Gene ontology: tool for the unification of biology. Nat Genet. 2000; 25:25-29. [PubMed: 10802651]

50. Benjamini Y, Hochberg Y. Controlling the false discovery rate: a practical and powerful approach to multiple testing. J R Stat Soc B. 1995; 57:289-300.

51. Cohen, J. Statistical Power Analysis for the Behavioral Sciences 24-27. Lawrence Erlbaum Associates; 1988. 

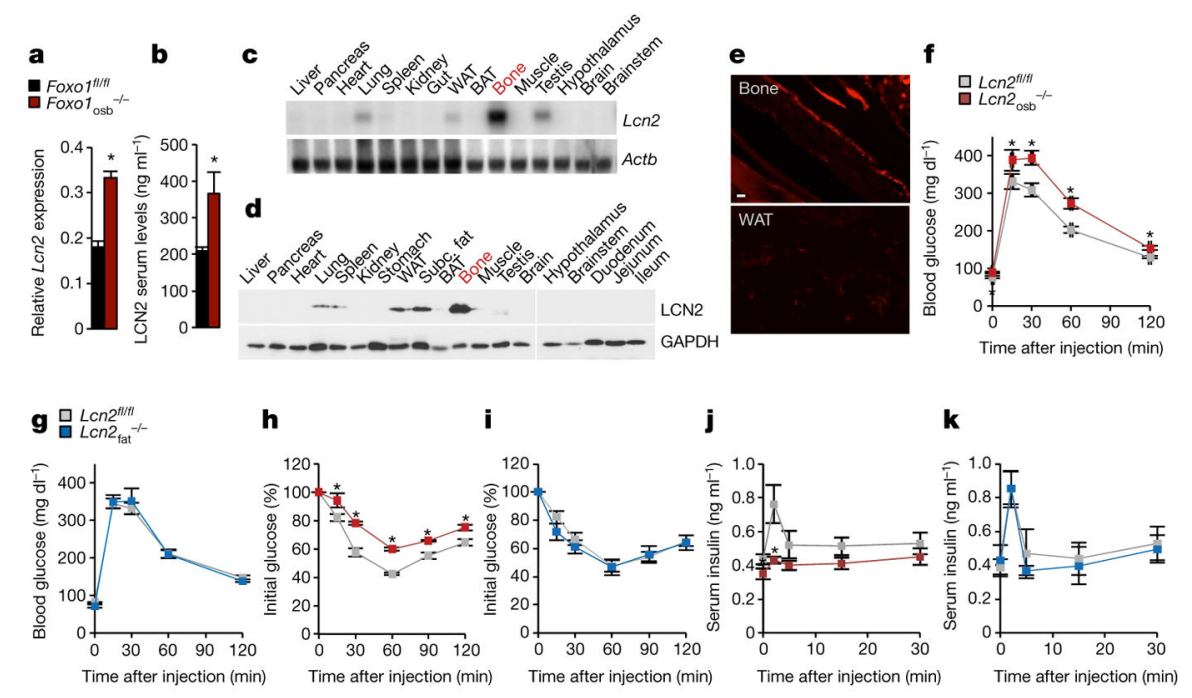

Figure 1. LCN2 regulates glucose homeostasis through its expression in osteoblasts a, mRNA expression of $L c n 2$ in bone. b, Serum levels of LCN2 in mice. $\mathbf{c}, \mathbf{d}$, mRNA and protein expression of LCN2 in wild-type (WT) tissues. BAT, brown adipose tissue; subc. fat, subcutaneous fat; WAT, white adipose tissue. c, Northern blot analysis of Lcn2 levels. Actb was used as a loading control. d, Western blot analysis of LCN2 levels. GAPDH was used as a loading control. e, LCN2 in bone and fat tissues of Lcn2-mCherry mice. Scale bar, $40 \mu \mathrm{m}$. $\mathbf{f}, \mathbf{g}$, Glucose-tolerance test of osteoblast-specific (f) or adipocyte-specific (g) Lcn2-knockout mice compared to wild-type $\left(L c n^{\mathrm{fl} / \mathrm{fl}}\right)$ littermates. $\mathbf{h}, \mathbf{i}$, Insulin-tolerance test of osteoblastspecific (h) or adipocyte-specific (i) $L c n 2$-knockout mice compared to wild-type $\left(L c n^{\mathrm{fl} / \mathrm{fl}}\right)$ littermates. j, k, Glucose-stimulated insulin secretion in osteoblast-specific (j) or adipocytespecific (k) Lcn2-knockout mice or wild-type littermates. Data are mean \pm s.e.m.; $n=10$ (a, b), $n=12(\mathbf{f}), n=7(\mathbf{g}, \mathbf{k}), n=6(\mathbf{h})$ and $n=8(\mathbf{i}, \mathbf{j})$ mice per group; representative of three independent experiments. In $\mathbf{f}, \mathbf{h}, \mathbf{j}$, the effect size $(d)>0.84 ; * P<0.05$ (Student's $t$-test). 

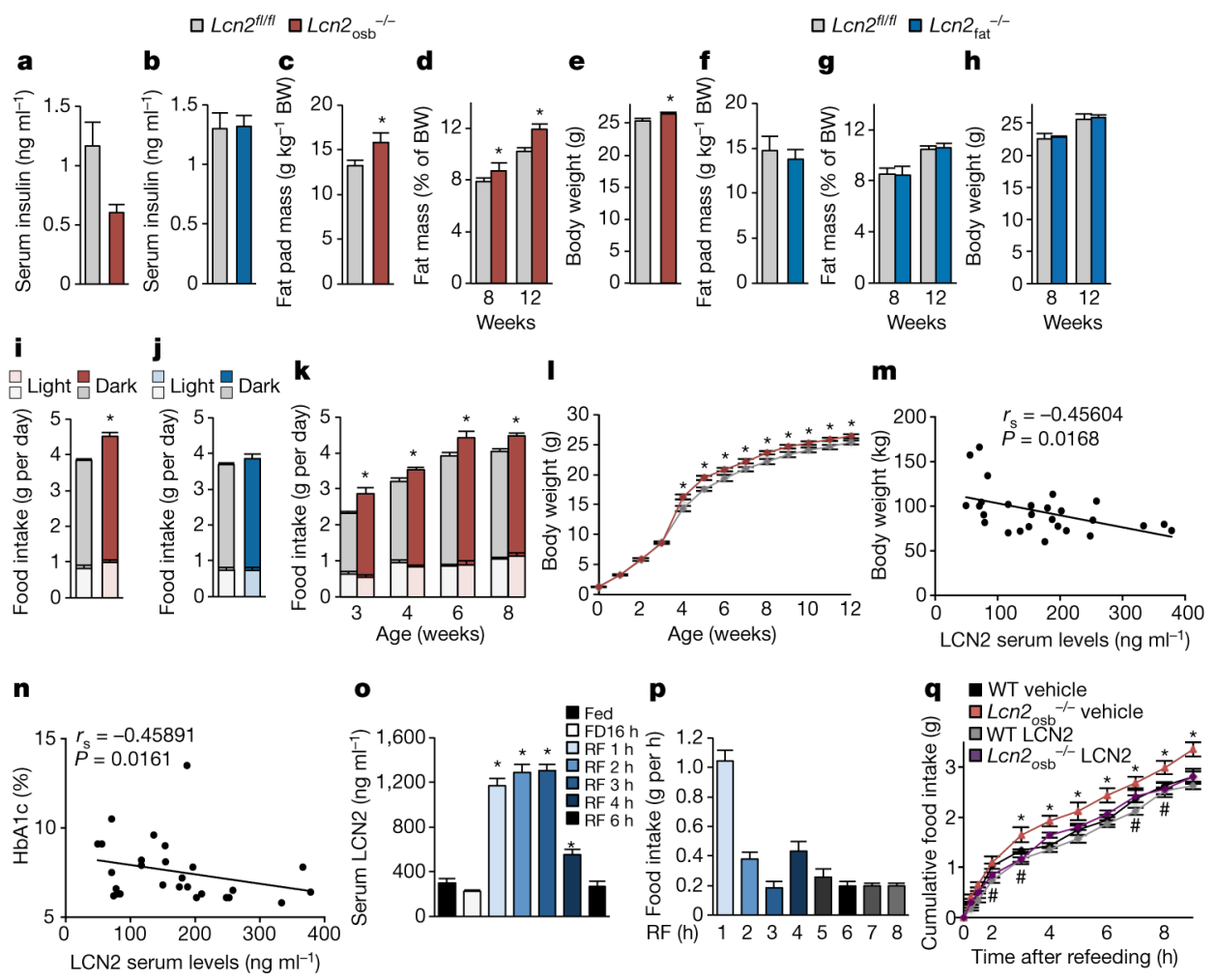

Figure 2. Inactivation of $L c n 2$ in osteoblasts increases food intake

a, b, Serum insulin levels of osteoblast-specific (a) or adipocyte-specific (b) Lcn2-knockout mice compared to wild-type $\left(L c n^{\mathrm{fl} / \mathrm{fl}}\right)$ littermates. $\mathbf{c}-\mathbf{l}$, Analysis of fat pad mass $(\mathbf{c}, \mathbf{f})$, body fat mass (d, g), body weight (BW; $\mathbf{e}, \mathbf{h}, \mathbf{l})$ and cumulative food intake $(\mathbf{i}, \mathbf{j}, \mathbf{k})$ of $L c n 2_{\mathrm{osb}^{-/-}}$ $(\mathbf{c}-\mathbf{e}, \mathbf{i}, \mathbf{k}, \mathbf{l})$ and $L c n 2_{\mathrm{fat}^{-}}{ }^{--}(\mathbf{f}-\mathbf{h}, \mathbf{j})$ mice. $\mathbf{m}, \mathbf{n}$ Body weight $(\mathbf{m})$ and $\mathrm{HbA}_{\mathrm{lc}}(\mathbf{n})$ inversely correlate with serum LCN2 levels in patients with type 2 diabetes. o, p, LCN2 serum levels (o) and food intake (p) in wild-type mice that were fast (FD) or fasted and refed (RF). $\mathbf{q}$, Food intake in $L \mathrm{cn} 2_{\mathrm{osb}^{-}}{ }^{-/}$mice that were fasted and refed after intraperitoneal LCN2 administration. Data are mean \pm s.e.m.; $n=11(\mathbf{a}, \mathbf{c}, \mathbf{o}), n=10(\mathbf{b}, \mathbf{d}), n=13(\mathbf{e}), n=8(\mathbf{f}, \mathbf{h})$, $n=7(\mathbf{g}, \mathbf{j}), n=9(\mathbf{i}, \mathbf{l}, \mathbf{p}), n=5(\mathbf{k})$ and $n=4(\mathbf{q})$ mice per group; representative of three independent experiments; $d>0.96(\mathbf{a}, \mathbf{c}, \mathbf{d}, \mathbf{i}, \mathbf{k})$ and $d>0.74(\mathbf{e}, \mathbf{l}) . \mathbf{a}, \mathbf{c}, \mathbf{d}, \mathbf{e}, \mathbf{i}, \mathbf{k}, \mathbf{l}, \mathbf{o}, * P<$ 0.05 (Student's $t$-test). q, $* P<0.05$, vehicle-treated $L c n 2_{\mathrm{osb}^{-}}{ }^{-/}$versus vehicle-treated wildtype mice and LCN2-treated $L c n 2_{\mathrm{osb}}{ }^{-1-}$ mice (ANOVA); and \#P<0.05, LCN2-treated wildtype mice versus vehicle-treated wild-type mice (Student's $t$-test). 

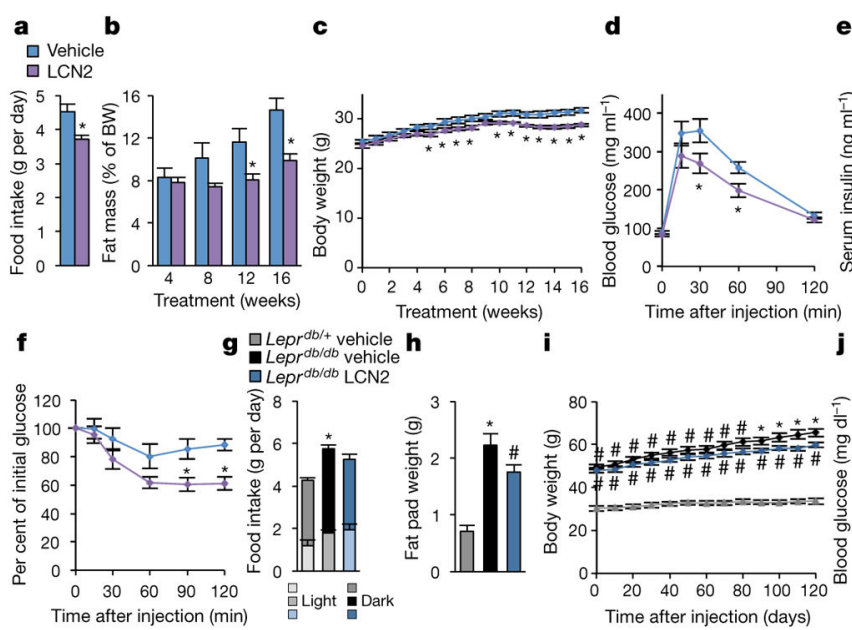

h
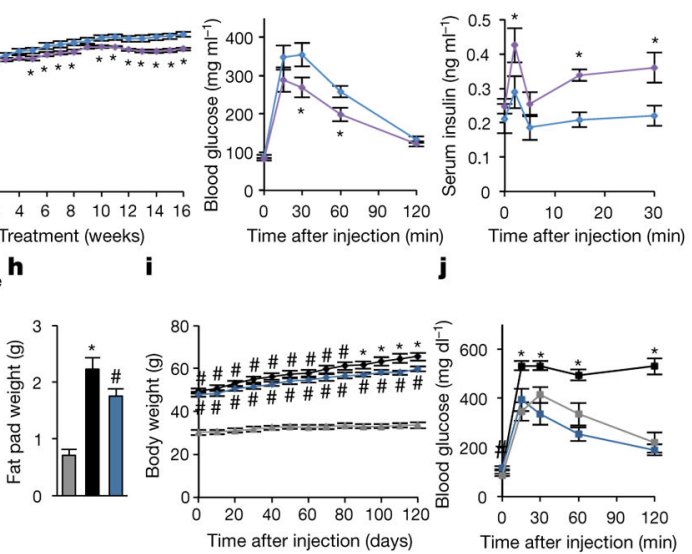

Figure 3. LCN2 suppresses food intake in lean and obese mice

a, Daily food intake of wild-type mice treated with vehicle or LCN2. b, c, h, i, Analysis of fat mass $(\mathbf{b}, \mathbf{h})$ and body weight $(\mathbf{c}, \mathbf{i})$ of wild-type or $L e p r^{d b / d b}$ mice treated with vehicle or LCN2. g, Cumulative (for the two phases, dark and light) daily food intake of wild-type or $L e p r^{d b / d b}$ mice treated with vehicle or LCN2 during different light phases of the day. $\mathbf{d}-\mathbf{f}, \mathbf{j}$, Glucose-tolerance test (d, $\mathbf{j})$, glucose-stimulated insulin secretion (e), insulin-tolerance test (f) of wild-type or $L e p r^{d b / d b}$ mice treated with LCN2. Data are mean \pm s.e.m.; $n=8$ wildtype and $n=6 \mathrm{Lepr}{ }^{d b / d b}$ mice; representative of three independent experiments. a-g, ${ }^{*} P<$ 0.05 (Student's $t$-test). $\mathbf{h}-\mathbf{j}, \# P<0.05, L$ epr ${ }^{d b / d b}$ versus $L e p r^{d b /+}$ mice treated with vehicle (Student's $t$-test). $* P<0.05$, Lepr $^{d b / d b}$ vehicle versus Lepr ${ }^{d b /+}$ (vehicle) and $L e p r^{d b / d b}$ (LCN2) groups (ANOVA). 

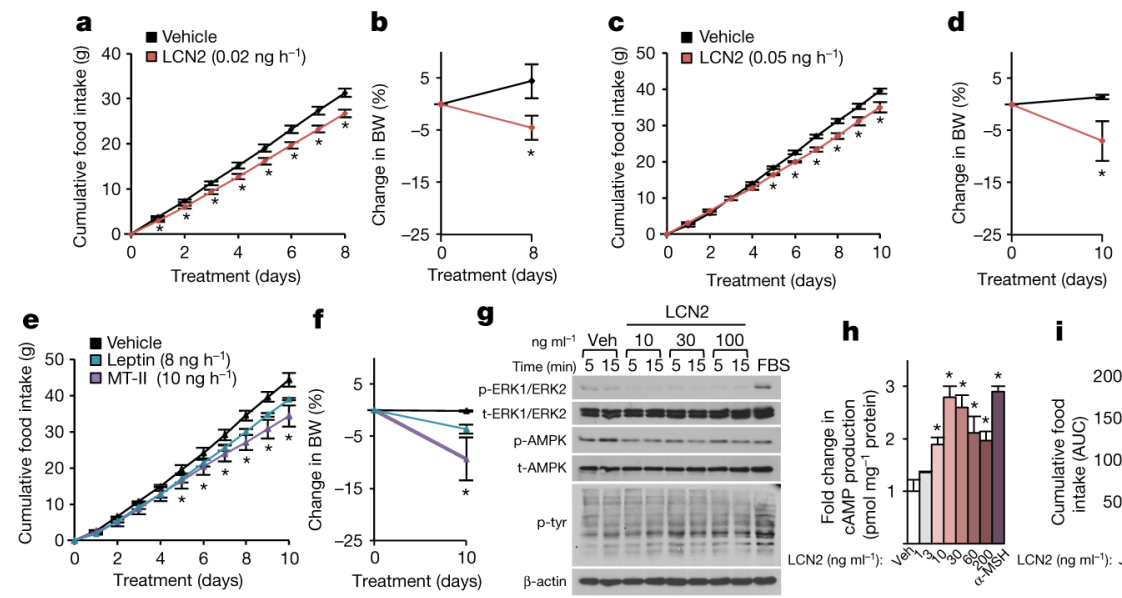

$\mathbf{g}$

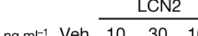

$\mathrm{ng} \mathrm{ml}^{-1}$ Veh $\frac{10}{20} \frac{30}{10} \frac{100}{5}$

$\mathbf{h}$ Time $(\min )$
p-ERK $1 /$ ERK2 t-ERK1/ER
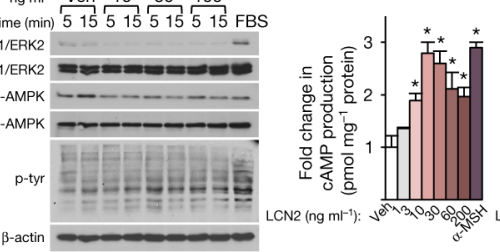

i

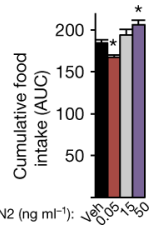

Figure 4. LCN2 signals directly in the brain to suppress food intake a-f, i, Change in food intake (a, c, e, i) and body weight $(\mathbf{b}, \mathbf{d}, \mathbf{f})$ in $L c n 2^{-/-}$or wild-type mice during ICV administration of LCN2 (a-d, i), leptin or MT-II (e, f). AUC, area under the curve. g, Western blot analysis of phosphorylated (p-) or total (t-) AMPK, ERK1/ERK2 and tyrosine kinase (tyr). $\beta$-actin was used as a loading control. Veh, vehicle; FBS, fetal bovine serum. $\mathbf{h}$, cAMP production in GT1-7 cells after treatment with LCN2 or a-MSH. In i, data from c for vehicle and low-LCN2 are included. Data are mean \pm s.e.m.; $n=6(\mathbf{a}, \mathbf{b}), n$ $=10(\mathbf{c}, \mathbf{d}, \mathbf{i})$ and $n=5(\mathbf{e}, \mathbf{f})$ mice per group; $n=3(\mathbf{h})$; representative of three independent experiments. $* P<0.05$ (Student's $t$-test). 


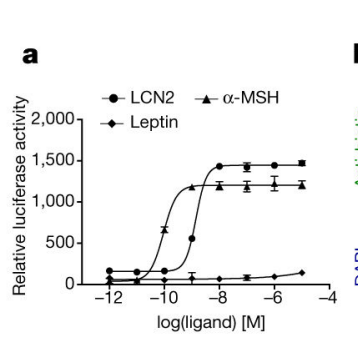

c
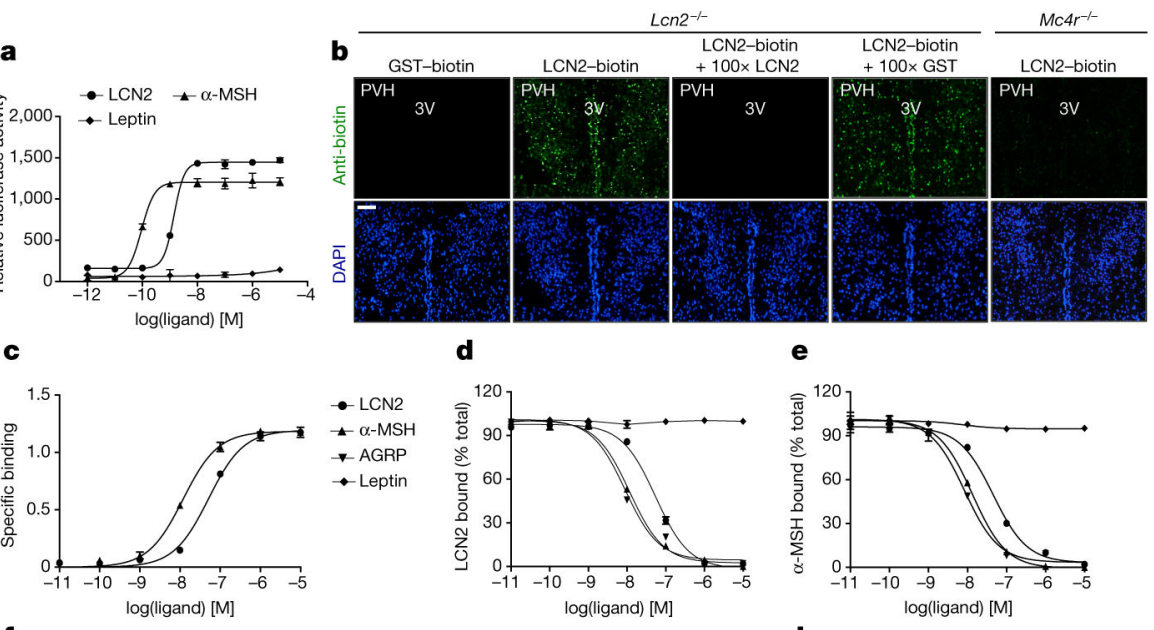

d

e

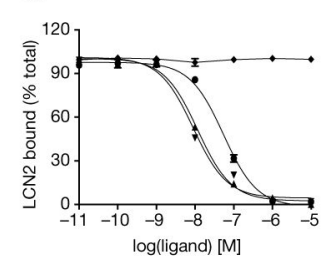

g sim-Cre:tctomato

- LCN2

$\neq \alpha-\mathrm{MSH}$
$\rightarrow \mathrm{AGRP}$

$\rightarrow$ Leptin
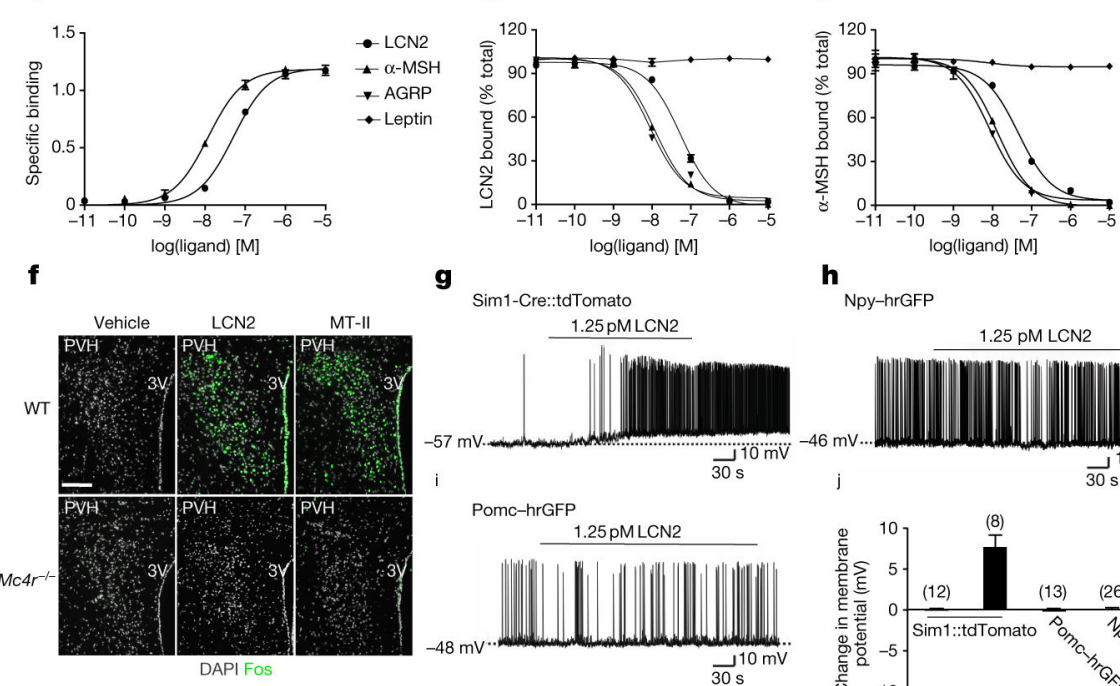

h

Npy-hrGFP
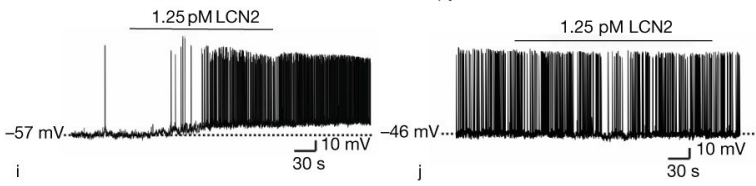

Pomc-hrGFP
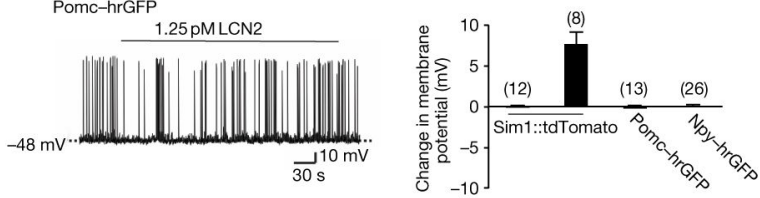

Figure 5. LCN2 binds to and signals through MC4R in the hypothalamus

a, cAMP production of HEK293T cells overexpressing MC4R after treatment with LCN2, leptin or a-MSH b, Binding of biotinylated LCN2 or GST (control) to hypothalamic sections from $\mathrm{Lcn}^{-/-}$or $\mathrm{Mc} 4 \mathrm{r}^{-/-}$mice in the presence or absence of 100-fold excess of non-biotinylated LCN2 or GST. PVH, paraventricular nucleus of the hypothalamus; 3V, third ventricle. c-e, Saturation (c) and competitive binding (d, e) assay curves of LCN2 and a-MSH in $M c 4 r$-transfected HEK293T cells. Leptin and AGRP were used as a negative and additional positive control, respectively. f, Fos expression in the PVH of wild-type and $M c 4 r$ -I- mice treated with LCN2 or MT-II. $\mathbf{g}-\mathbf{j}$, Representative traces $(\mathbf{g}-\mathbf{i})$ and change in resting membrane potential (j) of neurons after LCN2 treatment. LCN2 treatment induced depolarization in a Sim1-cre:ttdTomato (g) but not $N p y$-hrGFP (humanized renilla green fluorescent protein) (h) or Pomc-hrGFP (i) neuron. Scale bars, $100 \mu \mathrm{m}$. Data are mean \pm s.e.m.; representative of three independent experiments. ${ }^{*} P<0.05$ (Student's $t$-test). 


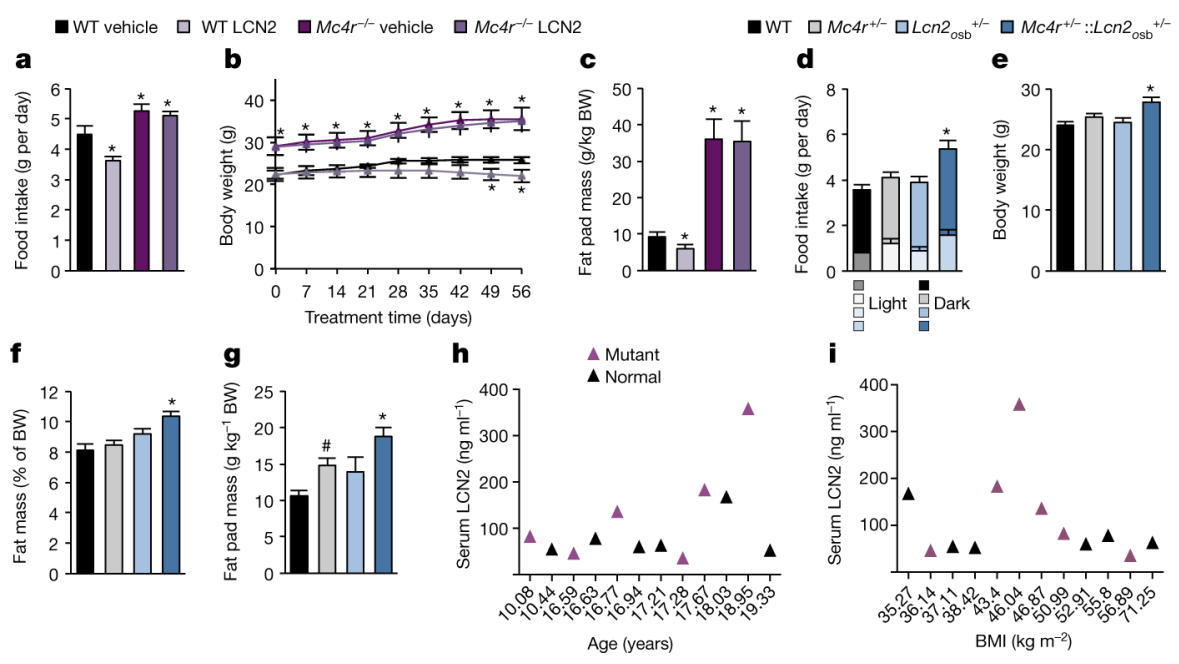

Figure 6. MC4R mediates suppression of appetite by osteoblast-derived LCN2

$\mathbf{a}-\mathbf{f}$, Analysis of food intake $(\mathbf{a}, \mathbf{d})$, body weight $(\mathbf{b}, \mathbf{e})$, fat pad mass $(\mathbf{c}, \mathbf{g})$ and body fat mass (f) in $M c 4 r^{-1-}$ mice treated with LCN2 for 8 weeks(a-c) or in $M c 4 r^{+/-}, L c n 2_{\mathrm{osb}}{ }^{+/-}, M c 4 r$ ${ }^{+/-}:: L c n 2_{\text {osb }}{ }^{+/-}$and wild-type littermates (d-g). h, i, LCN2 plasma levels in patients with mutated and normal $M C 4 R$ at different ages (h) and body-mass indexes (i). Data are mean ts.e.m.; $n=5$ wild-type and $n=8 M c 4 r^{-1-}$ mice (a-c), $n=7$ wild-type, $M c 4 r^{+/-}$and $M c 4 r$ ${ }^{+/-}:: L c n 2_{\mathrm{osb}^{+}}{ }^{+/-}$mice and $n=5 L \mathrm{Lcn} 2_{\mathrm{osb}^{+/-}}$mice $(\mathbf{d}-\mathbf{g})$; representative of three independent experiments. a-c, ${ }^{*} P<0.05$, vehicle-treated wild-type mice compared to the other groups; d-g, $* P<0.05, M c 4 r^{+/-}:: L c n 2_{\mathrm{osb}}{ }^{+/-}$mice versus wild-type, $M c 4 \mathrm{r}^{+/-}$and $L c n 2_{\mathrm{osb}}{ }^{+/-}$mice (ANOVA); ${ }^{\#} P<0.05, M c^{+t /-}$ versus wild-type mice (Student's $t$-test). 